\title{
Effects of Adoptive Transfer of Tolerogenic Dendritic Cells on Allograft Survival in Organ Transplantation Models: An Overview of Systematic Reviews
}

\author{
Yanni Zhou, ${ }^{1}$ Juan Shan, ${ }^{1}$ Yingjia Guo, ${ }^{1}$ Shengfu Li, ${ }^{1}$ Dan Long, ${ }^{1}$ Youping Li, ${ }^{1,2}$ and Li Feng ${ }^{1}$ \\ ${ }^{1}$ Key Laboratory of Transplant Engineering and Immunology of The Ministry of Health, Regenerative Medical Research Centre, \\ West China Hospital, Sichuan University, Chengdu 610041, China \\ ${ }^{2}$ Chinese Cochrane Centre, Chinese Evidence-Based Medicine Centre, West China Hospital, Sichuan University, \\ Chengdu 610041, China
}

Correspondence should be addressed to Youping Li; yzmylab@hotmail.com and Li Feng; 414229253@qq.com

Received 18 February 2016; Revised 6 May 2016; Accepted 12 May 2016

Academic Editor: Marco Velasco

Copyright ( 2016 Yanni Zhou et al. This is an open access article distributed under the Creative Commons Attribution License, which permits unrestricted use, distribution, and reproduction in any medium, provided the original work is properly cited.

Objective. To dissect the efficacy of Tol-DC therapy with or without IS in multiple animal models of transplantation. Methods and Results. PubMed, Medline, Embase, and the Cochrane Library were searched for reviews published up to April 2015. Six systematic reviews and a total of 61 articles were finally included. Data were grouped by organ transplantation models and applied to metaanalysis. Our meta-analysis shows that Tol-DC therapy successfully prolonged allograft survival to varying extents in all except the islet transplantation models and with IS drugs further prolonged the survival of heart, skin, and islet allografts in mice, but not of heart allografts in rats. Compared with IS drugs alone, Tol-DC therapy with IS extended islet allograft survival in rats but failed to influence the survival of skin, small intestine, and heart allografts in rats or of heart and skin allografts in mice. Conclusion. Tol-DC therapy significantly prolonged multiple allograft survival and further prolonged survival with IS. However, standardized protocols for modification of Tol-DC should be established before its application in clinic.

\section{Introduction}

Transplantation is one of the most effective methods of extending life for patients with end-stage organ failure. However, the immunosuppressive (IS) agents commonly used to prevent graft-versus-host disease and host-versus-graft disease compromise the recipient's immune system and are associated with side effects such as infection and recurrence of disease, thus decreasing the patient's quality of life. For this reason, induction of donor-specific tolerance without impairment of immune defense remains the holy grail of transplantation research.

Dendritic cells (DCs), first described in 1973 [1], are the most effective antigen-presenting cells and are key regulators of a balanced immune system by virtue of their dual immunogenic and tolerogenic functions. Immunogenic DCs have been developed as positive therapeutic vaccines to elicit antitumor responses. The first DC vaccine, sipuleucel-T
(PROVENGE ${ }^{\circledR}$ ), was approved by the FDA in 2010 and has since been successfully used in prostate cancer treatment [2]. In contrast, tolerogenic DCs (Tol-DCs) lack essential costimulatory signals and/or express inhibitory signals and play a role in tolerance induction. Evidence indicates that Tol-DCs have great therapeutic potential in autoimmunity and allergy [3]. To date, several phase I trials assessing safety of TolDCs in rheumatoid arthritis and refractory Crohn's disease patients were conducted $[4,5]$. Moreover, mounting evidence shows that Tol-DCs are able to induce donor-specific $\mathrm{T}$ cell hyporesponsiveness and prolong allograft survival. As such, negative vaccines based on Tol-DCs have great potential to prevent transplant rejection. The safety of autologous TolDCs has so far been demonstrated in type I diabetes patients [6] and is currently being tested by Moreau et al. in kidney transplant recipients [7]. However, whether Tol-DCs can effectively prolong allograft survival and show superiority to other forms of IS therapy remains controversial. Here, 
we present the results of a meta-analysis of the efficacy of Tol-DCs in multiple animal models of transplantation. We evaluated allograft survival time after treatment with Tol-DCs alone, compared the relative superiority of single therapy with Tol-DCs or IS, and looked for evidence of synergy between Tol-DC and IS therapy in promoting allograft survival.

\section{Methods}

2.1. Criteria for Considering Reviews for Inclusion and Exclusion. We included systematic reviews that focused on the effects of Tol-DC injection on allograft survival compared with untreated groups in any kind of transplantation model. To be included, the reviews had to describe the outcome of interest.

2.2. Search Methods for Identification of Reviews. Comprehensive literature searches were conducted in PubMed, Medline, Embase, and the Cochrane Library from database inception until April 2015. We identified relevant systematic reviews using the following as $\mathrm{MeSH}$ or text words: "transplantation," "dendritic cells," "tolerance," and "review." To ensure comprehensive and up-to-date coverage of the evidence base and to make recommendations for future reviews, we also searched for and considered primary articles that were potentially eligible for, but not yet included in, published reviews.

2.3. Selection of Reviews and Articles. We screened reviews according to the inclusion criteria above and also included new primary studies, excluding duplicates and those already included in the reviews. For primary articles, we included only those that provided data applicable to meta-analysis on (i) Tol-DCs versus untreated and/or (ii) Tol-DCs in combination with IS agents (including immunosuppressive drugs and/or costimulatory blockers) versus Tol-DCs alone and (iii) Tol-DCs in combination with IS agents versus IS alone. We also excluded studies that were included in the reviews but did not provide data applicable to meta-analysis.

2.4. Data Extraction. For the eligible reviews, two reviewers independently extracted information on author name, publication year, transplantation model, outcomes measured, whether a meta-analysis was conducted, and quality assessment of the original articles. For primary articles, information was extracted on transplantation model, interventions, group comparisons, and outcomes measured. Disagreements were resolved by consensus.

2.5. Quality Assessment of Systematic Reviews. The methodological quality of the included systematic reviews was appraised by two independent reviewers using the Assessment of Multiple Systematic Reviews (AMSTAR) tool [9]. AMSTAR consists of 11 questions, each with "Yes," "No," "Can't Answer," or "Not Applicable" answers, and checks for the following items: (1) "a priori" study design; (2) duplicate reviewers for study selection and data extraction; (3) comprehensive literature search; (4) publication status as an inclusion criterion (i.e., gray or unpublished literature); (5) list of studies included/excluded; (6) characteristics of the included studies; (7) scientific quality assessment and documentation; (8) appropriate formulation of conclusions (based on methodological rigor and scientific quality of the studies); (9) appropriate methods of combining studies (homogeneity test, effects model, and sensitivity analysis); (10) assessment of publication bias (graphic and/or statistical test); and (11) inclusion of conflict of interest statement. Disagreements were resolved by consensus.

2.6. Data Synthesis. Data were divided into six groups according to the transplantation model and then further divided into subgroups based on animal species. For each model, we grouped the data by intervention as follows: TolDCs versus untreated, Tol-DCs in combination with IS versus Tol-DCs, and Tol-DCs in combination with IS versus IS. The primary end point of our meta-analysis was allograft survival time. For each study, we calculated the summary mean difference and 95\% confidence intervals (CI) for the end point. We pooled studies using a random effects model, making the assumption that individual studies estimated different treatment effects. We examined heterogeneity in the main analysis and subgroup analysis by $Q$ statistic and $I^{2}$ index. Three articles were excluded from our summary table (Table 3) and discussion because they contained only a single set of data and the evidence was too weak to be included [16-18]. However, data from those articles are mentioned individually in the Results.

\subsection{Ethics. No ethical approval was required.}

\section{Results}

3.1. Results of Search and Selection. Our research identified 1121 reports, of which 87 were excluded as duplicates. Screening by the titles and abstracts, we excluded 1027 articles for irrelevant themes or unwanted article types and 7 were selected to be read in their entirety. Of those, 1 systematic review was excluded for irrelevant theme and 6 systematic reviews assessing the efficacy of Tol-DC treatment in animal models of heart, liver, kidney, small intestine, skin, and islet transplantation satisfied our inclusion and exclusion criteria and were further evaluated (Figure 1) [10-15]. Of the 112 studies included in the six systematic reviews, 65 studies were excluded because of inadequate data for meta-analysis (heart 28 , skin 16 , kidney 9 , islet 8 , small intestine 3 , and liver 2 ), and the remaining 47 studies were included in our overview [8, $16,17,19-63]$. We also included 14 newly identified primary articles (heart $8[64-71]$, skin $3[8,71,72]$, and islet $3[18,73$, 74]). Thus, we evaluated a total of 61 studies (Table 1 ).

3.2. Description of Included Reviews. Of the six included reviews, which were published between 2012 and 2014, only one conducted a meta-analysis [10-15]. The remaining five had incomplete information, such as omission of sample size or standard deviation, and applied semiquantitative methods to analyze the collected data. The kidney and islet 


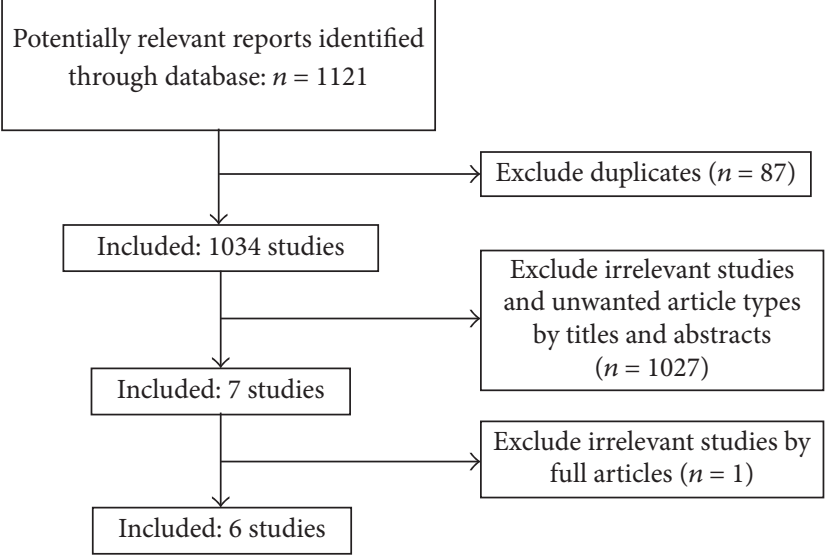

FIGURE 1: Flow diagram of searching and selection for included systematic reviews.

transplantation studies included both mouse and rat models, whereas the skin and heart studies included only mouse models and the small intestine and liver studies included only rat models (Table 1). Studies using either model were eligible for our overview.

3.3. Methodological Quality of Included Reviews. We assessed the methodological quality of the six included reviews using AMSTAR. The scores ranged from 5 to 8 , with points deducted for Item 4 (status of the publication as an inclusion criterion), Item 5 (list of studies included/excluded), Item 9 (appropriate methods of combining studies), and Item 10 (assessment of publication bias) (Table 2). Although the systematic reviews are of only moderate to high quality, it should be borne in mind that there are no conventional criteria for quality assessment of animal studies and no clinical data are available for an equivalent analysis of humans.

\subsection{Effects of Interventions on the Survival of Organ Allografts}

3.4.1. Liver Transplantation Models. In rats, infusion of TolDCs promoted liver allograft survival for an additional 18 days compared with no treatment (mean and 95\% CI; 18.17, 11.02 to 25.33) (Figure 3). One study (excluded from the overall evaluation) reported that Tol-DC + IS therapy was more effective in prolonging graft survival than either TolDCs or IS alone (mean \pm SD, 112 days \pm 19.0 versus $58 \pm 3.7$ versus $54 \pm 2.4$, resp.) [16].

3.4.2. Renal Transplantation Models. Tol-DC therapy prolonged renal graft survival by 17 days in rats $(17.72,13.35$ to 22.10) (Figure 3). Moreover, one study reported that Tol-DCs + IS extended graft survival significantly longer than Tol-DCs or IS alone ( 38.7 days \pm 40.0 versus $5.0 \pm 2.2$ versus $7.5 \pm 1.2$, resp.) [17].

3.4.3. Heart Transplantation Models. Heart grafts survived 14 days longer in Tol-DC-infused rats than in untreated rats
(14.21, 6.11 to 22.31) (Figure 2). However, Tol-DC + IS therapy failed to further prolong allograft survival compared with Tol-DCs alone (60.21 days, -43.78 to 164.20$)$ (Figure 4) or IS alone (57.56 days, -59.15 to 174.27) (Figure 5). In mice, infusion of Tol-DCs extended graft survival by 11 days (11.61, 7.73 to 15.49 ) (Figure 2). Tol-DC + IS therapy extended graft survival compared with Tol-DCs alone (5.05 days, 1.53 to 8.57) (Figure 4) but not with IS alone (1.72 days, -3.67 to 7.10 ) (Figure 5).

3.4.4. Small Intestine Transplantation Models. In rats, Tol-DC therapy prolonged graft survival by 8 days $(8.89,6.16$ to 11.61$)$ (Figure 3); however, Tol-DC + IS therapy failed to promote graft survival longer than IS therapy alone (8.97 days, -3.75 to 21.07) (Figure 5).

3.4.5. Islet Transplantation Models. Infusion of Tol-DCs failed to prolong allograft survival in rats (7.28 days, -2.91 to 17.46) (Figure 3). However, Tol-DC + IS therapy was significantly better than Tol-DCs or IS alone in prolonging graft survival (137.49 days, 96.59 to 178.40 and 177.83 days, 160.05 to 195.62, resp.) (Figures 4 and 5). In mice, Tol-DC therapy prolonged allograft survival by 6 days $(6.81,2.97$ to 10.64) (Figure 3). One included study reported that Tol-DCs + IS facilitated graft survival for significantly longer than TolDCs or IS alone (77.4 days \pm 10.7 versus $24.9 \pm 4.5$ versus $38.9 \pm 6.1$, resp.) [18].

3.4.6. Skin Transplantation Models. The systematic reviews did not include studies of the effects of Tol-DC therapy alone on skin allograft survival in rats. Nevertheless, our analysis indicates that graft survival was no better in rats treated with Tol-DC + IS therapy than with IS alone (7.15 days, -3.84 to 18.13) (Figure 5). In mice, Tol-DC therapy prolonged graft survival by 5 days (5.45, 2.31 to 8.59) (Figure 3), and Tol-DCs + IS had a significantly better outcome compared with TolDCs alone (3.84 days, 3.40 to 4.29) (Figure 4) but not with IS alone ( 0.45 days, 0.00 to 0.89 ) (Figure 5 ). 
TABLE 1: Characteristics of included systematic reviews.

\begin{tabular}{|c|c|c|c|c|c|c|c|c|}
\hline \multirow{4}{*}{$\begin{array}{l}\text { Included reviews } \\
\text { Wu et al. } 2012 \text { [10] }\end{array}$} & \multirow{4}{*}{$\begin{array}{c}\text { Tx models } \\
\text { Heart }\end{array}$} & \multicolumn{2}{|c|}{ Animal models } & \multirow[t]{2}{*}{ Data synthesis } & \multirow{2}{*}{$\begin{array}{c}\begin{array}{c}\text { Included } \\
\text { studies }\end{array} \\
44\end{array}$} & \multirow{2}{*}{$\begin{array}{c}\begin{array}{c}\text { Excluded } \\
\text { studies }\end{array} \\
28\end{array}$} & \multirow{2}{*}{$\begin{array}{c}\begin{array}{c}\text { Potential } \\
\text { new } \\
\text { studies }\end{array} \\
2\end{array}$} & \multirow{2}{*}{$\begin{array}{c}\text { Final } \\
\text { included } \\
\text { studies }\end{array}$} \\
\hline & & Mice & Included & & & & & \\
\hline & & Rats & Not included & & 0 & 0 & 6 & \\
\hline & & Total & & Description & 44 & 28 & 8 & 24 \\
\hline \multirow{3}{*}{ Sun et al. 2012 [11] } & \multirow{3}{*}{ Islet } & Mice & Included & & 9 & 7 & 3 & \\
\hline & & Rats & Included & & 4 & 1 & 0 & \\
\hline & & Total & & Description & 13 & 8 & 3 & 8 \\
\hline \multirow{3}{*}{ Xia et al. 2014 [12] } & \multirow{3}{*}{ Liver } & Mice & Not reported & & 0 & 0 & 0 & \\
\hline & & Rats & Included & & 7 & 2 & 0 & \\
\hline & & Total & & Description & 7 & 2 & 0 & 5 \\
\hline \multirow{3}{*}{ Xia et al. 2013 [13] } & \multirow{3}{*}{ Renal } & Mice & Included & & 5 & 5 & 0 & \\
\hline & & Rats & Included & & 11 & 4 & 0 & \\
\hline & & Total & & Description & 16 & 9 & 0 & 7 \\
\hline \multirow{3}{*}{ Zhou et al. 2013 [14] } & \multirow{3}{*}{ Skin } & Mice & Included & & 21 & 15 & 3 & \\
\hline & & Rats & Not included & & 0 & 0 & 0 & \\
\hline & & Total & & Description & 21 & 15 & 3 & 9 \\
\hline \multirow{3}{*}{ Sun et al. 2013 [15] } & \multirow{3}{*}{ Small intestine } & Mice & Not reported & & 0 & 0 & 0 & \\
\hline & & Rats & Included & & 11 & 3 & 0 & \\
\hline & & Total & & $\begin{array}{l}\text { Description \& } \\
\text { meta-analysis }\end{array}$ & 11 & 3 & 0 & 8 \\
\hline Total & 5 & & & & 112 & 65 & 14 & 61 \\
\hline
\end{tabular}

TABLE 2: Methodological quality assessment of systematic review.

\begin{tabular}{|c|c|c|c|c|c|c|c|c|c|c|c|c|c|}
\hline \multirow[t]{2}{*}{ SR } & \multirow[t]{2}{*}{ Model } & \multicolumn{10}{|c|}{$\begin{array}{l}\text { Methodological quality assessment of the included systematic reviews, } \\
\text { AMSTAR items }\end{array}$} & \multirow[b]{2}{*}{11} & \multirow[b]{2}{*}{ Rating } \\
\hline & & 1 & 2 & 3 & 4 & 5 & 6 & 7 & 8 & 9 & 10 & & \\
\hline Sun et al. [15] & Small intestine & Yes & Yes & Yes & No & No & Yes & Yes & Yes & No & Yes & Yes & 8 \\
\hline Zhou et al. [14] & Skin & Yes & Yes & Yes & No & No & Yes & Yes & Yes & N/A & No & Yes & 7 \\
\hline Sun et al. [11] & Islet & Yes & Yes & Yes & No & No & Yes & Yes & Yes & N/A & No & Yes & 7 \\
\hline Wu et al. [10] & Heart & Yes & Yes & Yes & No & No & Yes & Yes & No & N/A & No & Yes & 6 \\
\hline Xia et al. [13] & Renal & Yes & No & Yes & No & No & Yes & Yes & Yes & N/A & No & Yes & 6 \\
\hline Xia et al. [12] & Liver & Yes & No & Yes & No & No & Yes & Yes & No & N/A & No & Yes & 5 \\
\hline Total & & 6 & 4 & 6 & 0 & 0 & 6 & 6 & 4 & 0 & 1 & 6 & \\
\hline$\%$ & & $100 \%$ & $67 \%$ & $100 \%$ & $0 \%$ & $0 \%$ & $100 \%$ & $100 \%$ & $67 \%$ & $0 \%$ & $17 \%$ & $100 \%$ & \\
\hline
\end{tabular}

N/A: not applicable. There are 11 items in total, "Yes" making 1 score and "No" or "N/A" 0.

\subsection{Effects of Different Interventions on Allograft Survival}

3.5.1. Tol-DCs versus No Treatment. Tol-DC therapy prolonged allograft survival in all transplantation models in rats and/or mice, with the exception of the islet transplantation model in rats. Ranked in order from longest to shortest allograft survival time, Tol-DC therapy was most efficacious for liver, kidney, heart, small intestine, and islet allografts in rats and heart, islet, and skin allografts in mice (Table 3, Figures 2 and 3).
3.5.2. Tol-DCs + IS versus Tol-DCs Alone. In rats, Tol-DCs + IS further prolonged the survival of islet allografts (137.49 days, 96.59 to 178.40 ), but not heart allografts (60.21 days, -43.78 to 164.20$)$, compared with Tol-DCs alone. In mice, Tol-DCs + IS were superior to Tol-DCs alone in prolonging survival of both heart and skin allografts (5.05 days, 1.53 to 8.57 versus 3.84 days, 3.40 to 4.29 , resp.) (Table 3 and Figure 4). Three studies of mouse islet [18], rat liver [16], and rat kidney [17] transplantation models reported better outcomes with Tol-DCs + IS than with Tol-DCs alone. 


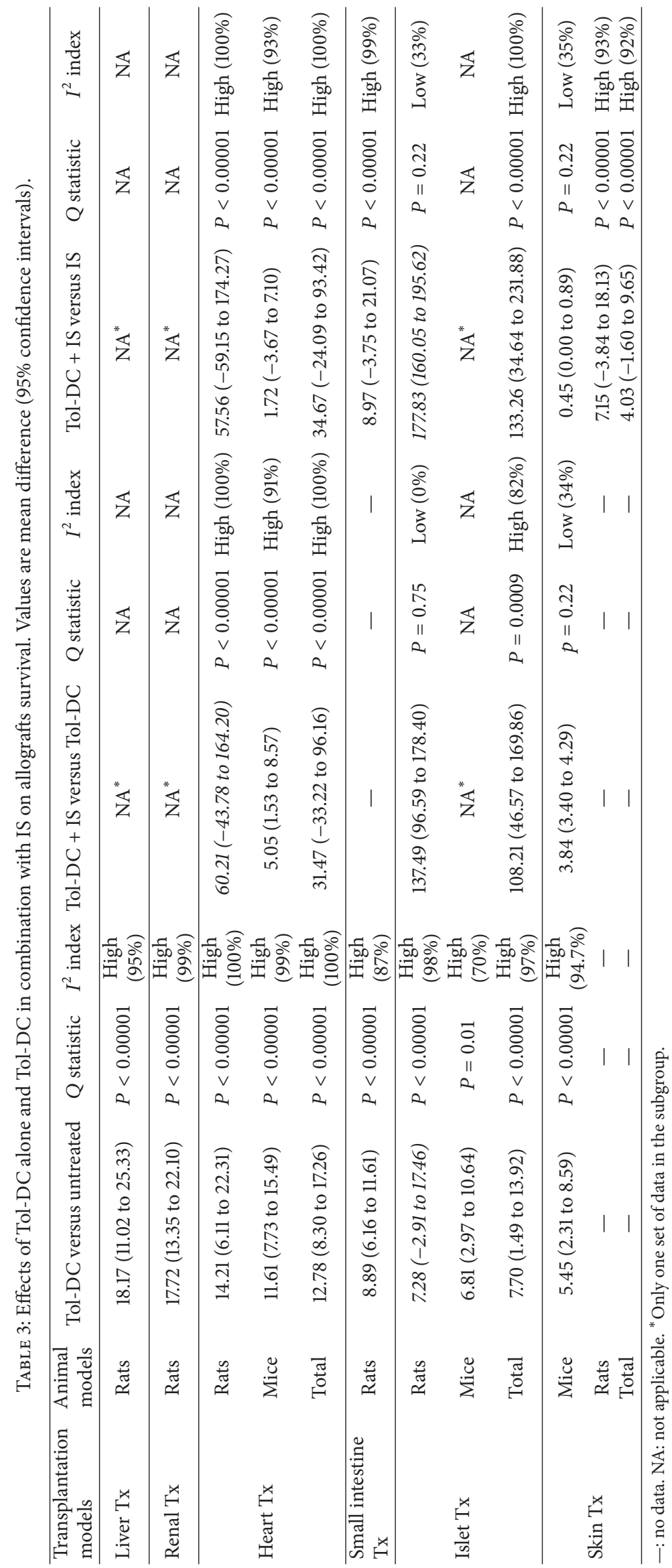




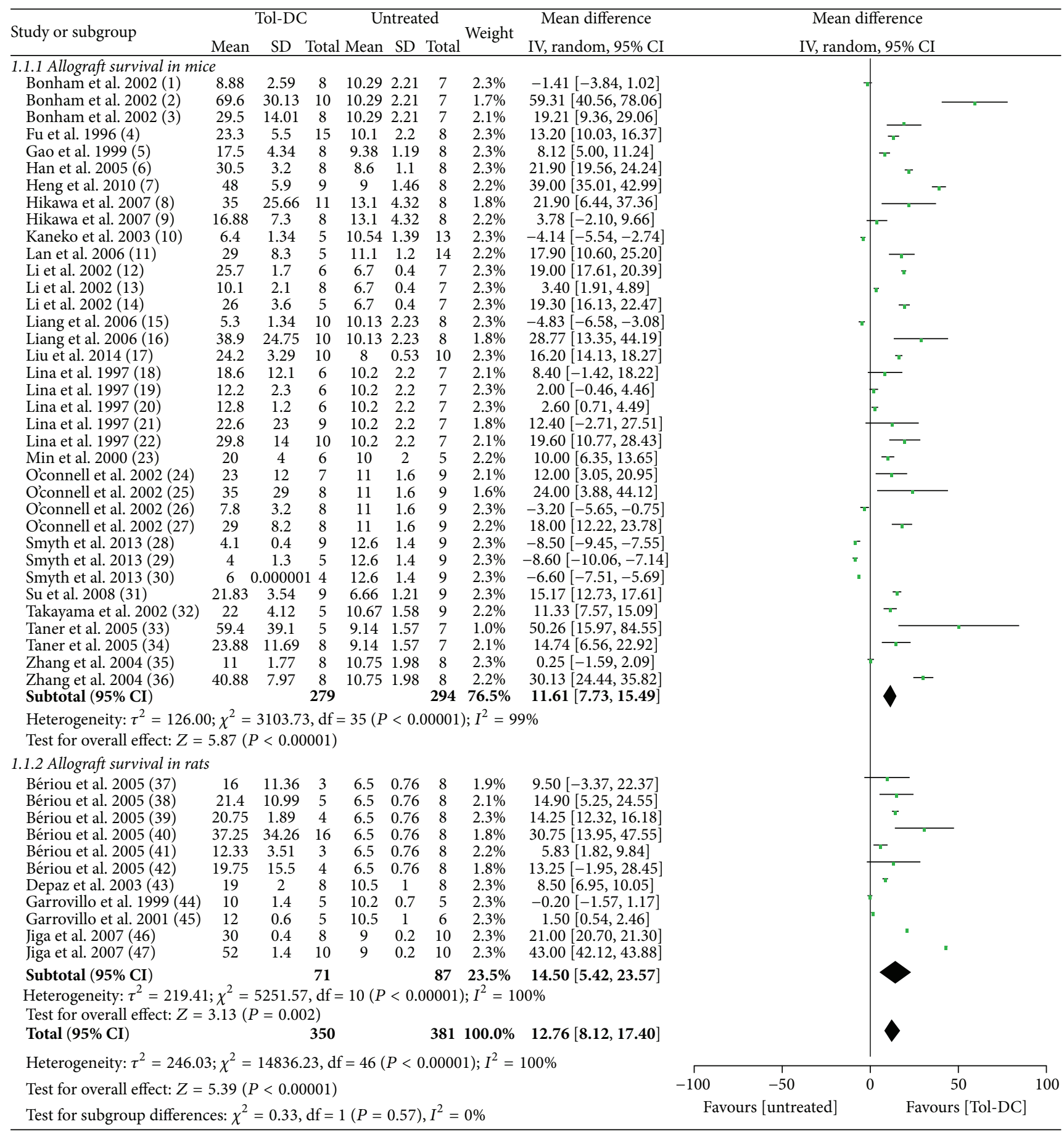

Footnotes

(1) CTLA4Ig-DC
(2) (si-NF- $k$ B decoy ODN+CTLA4Ig)-DC

(3) si-NF- $\kappa$ B decoy ODN-DC

(4) GM-CSF+DC

(5) Donor spleen DC coculture with leucocytes

6) Mycophenolate mofetil+DC

(7) FTY720+DC

(9) GM-CSF+IL-4+DC

(10) IL-4-DC

11) GM-CSF+IL-10+TGF- $\beta+$ LPS+DC

12) $\mathrm{IL}-4+\mathrm{GM}-\mathrm{CSF}+$ Mitomycin-C +DC

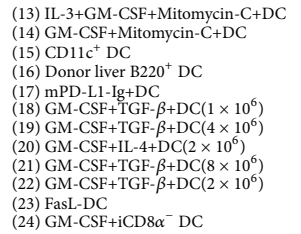

(25) GM-CSF+LPS+mCD $8 \alpha^{+} \mathrm{DC}$ (26) GM-CSF+LPS+mCD8 $\alpha^{-}$DC (27) GM-CSF+donor spleen iCD $8 \alpha^{+}$DC
(28) Dex+D3+LPS+DC(BD2F1) (29) $\mathrm{Dex}+\mathrm{D} 3+\mathrm{DC}(\mathrm{BALB} / \mathrm{c})$ (31) $\mathrm{Dex}+\mathrm{D} 3+\mathrm{DC}(\mathrm{B} 6 \mathrm{D} 2 \mathrm{c})$ (31) NBD peptide+
(32) TGF- $\beta 1$-DC

(33) AlloAg+Rapa+DC(injection on days $-10,-3$, and 0 (34) AlloAg+Rapa+DC(injection on day -7 ) (35) IL-10-DC(i.v.)
(37) $\mathrm{DC}\left(7 \times 10^{6}\right.$, injection on days -1 and 4$)$ (38) DC $\left(15 \times 10^{6}\right)$

(39) $\mathrm{DC}\left(3 \times 10^{6}\right)$

(40) $\mathrm{DC}\left(7 \times 10^{6}\right.$, injection on days -1$)$ (41) $\mathrm{DC}\left(7 \times 10^{6}\right.$, injection on days $-1,6$, and 13$)$ (42) $\mathrm{DC}\left(7 \times 10^{6}\right.$, injection on
(43) Low dose GM-CSF+DC

(44) Donor MHCI peptide+ recipient BMDC (45) Donor MHCI peptide+ recipient thymus DC

(47) Anti-CD80/86/ICAM1+Mitomycin+DC

Figure 2: Mean difference (95\% confidence intervals) for Tol-DC infusion versus untreated groups for allografts survival in heart. All studies involved used MHC complete mismatch models either in rats or in mice. In the footnotes, "- before "DC" means genetic modification and "+" means substances added in the culture medium. If not specialized, DC refers to donor bone borrow DC; when injection time is involved, we take the transplantation day as day 0. i.v.: intravenous; p.v.: portal vein. 


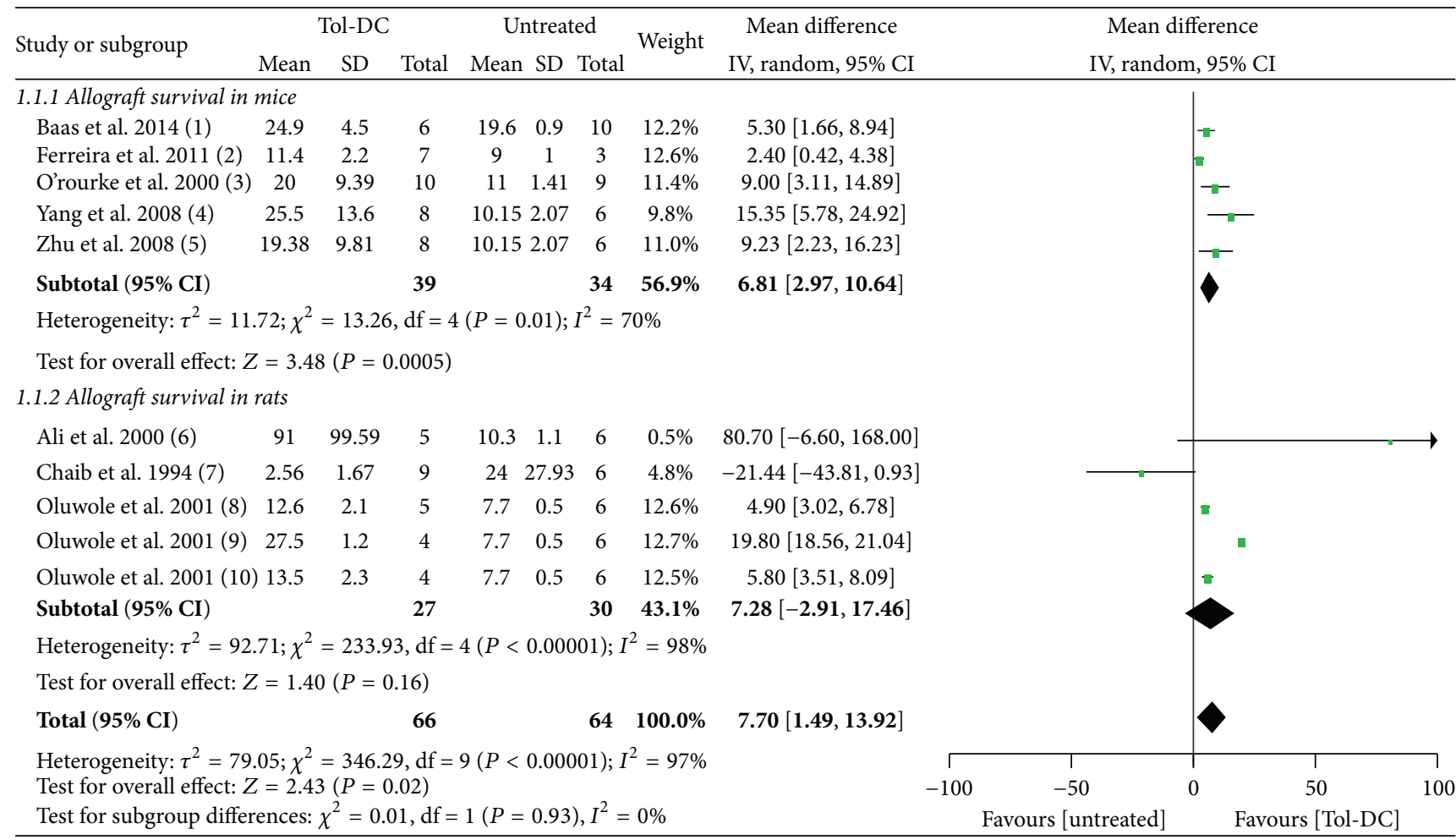

\section{Footnotes}

(1) GM-CSF+recipient adherent BMDC

(2) IFN $\gamma+\mathrm{LPS}+1,25 \mathrm{D}_{3}+$ donor Ag+recipient BMDC

(3) CTLA4Ig-DC(donor-derived cell line)

(8) Donor MHC I peptide+recipient $\operatorname{BMDC}\left(1 \times 10^{6}\right)$

(4) Donor thymic CTLA4Ig-DC

(a) Islet transplantation

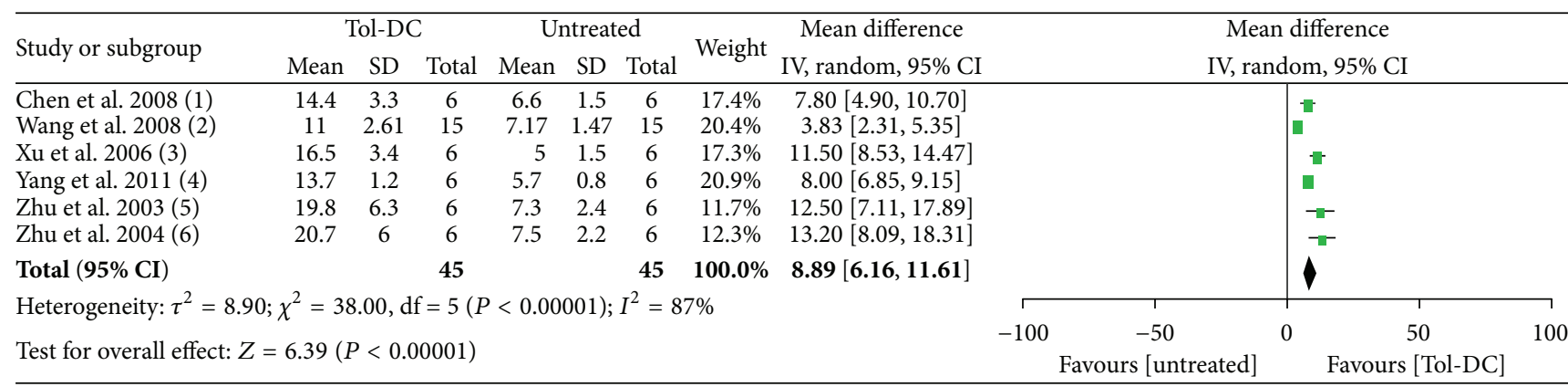

Footnotes

(1) Triptolide+DC (4) LPS+si-MyD88-DC

$\begin{array}{ll}\text { (2) iBMDC } & \text { (5) Donor spleen IL10-DC }\end{array}$

$\begin{array}{ll}\text { (3) si-IL-12 p35-DC } & \text { (6) IL10-DC }\end{array}$

(b) Small intestine transplantation in rats

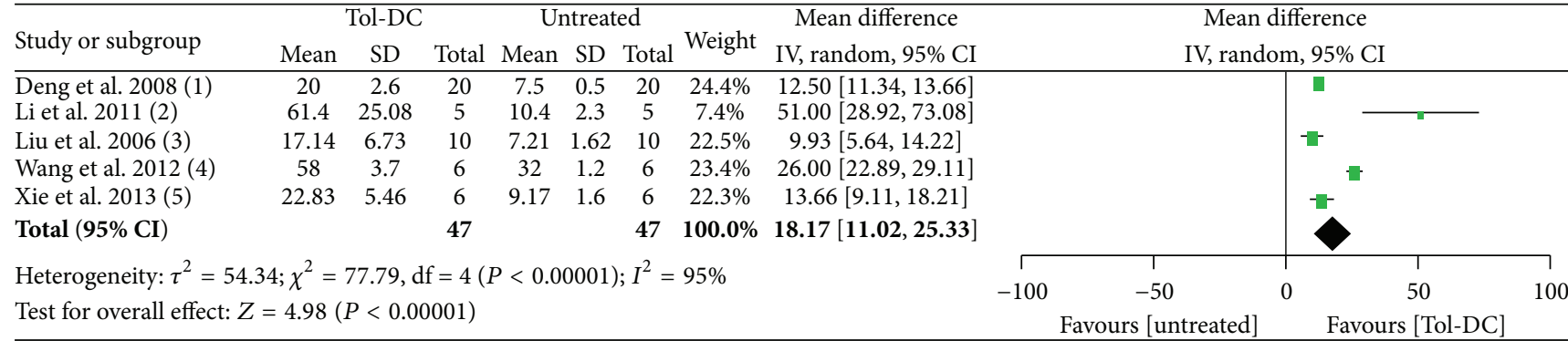

\begin{tabular}{ll}
\hline Footnotes & \\
(1) IL-10+DC & (4) iBMDC \\
(2) IL-10+recipient BMDC & (5) si-RelB-DC \\
(3) TGF- $\beta$-DC &
\end{tabular}

(c) Liver transplantation in rats

Figure 3: Continued. 


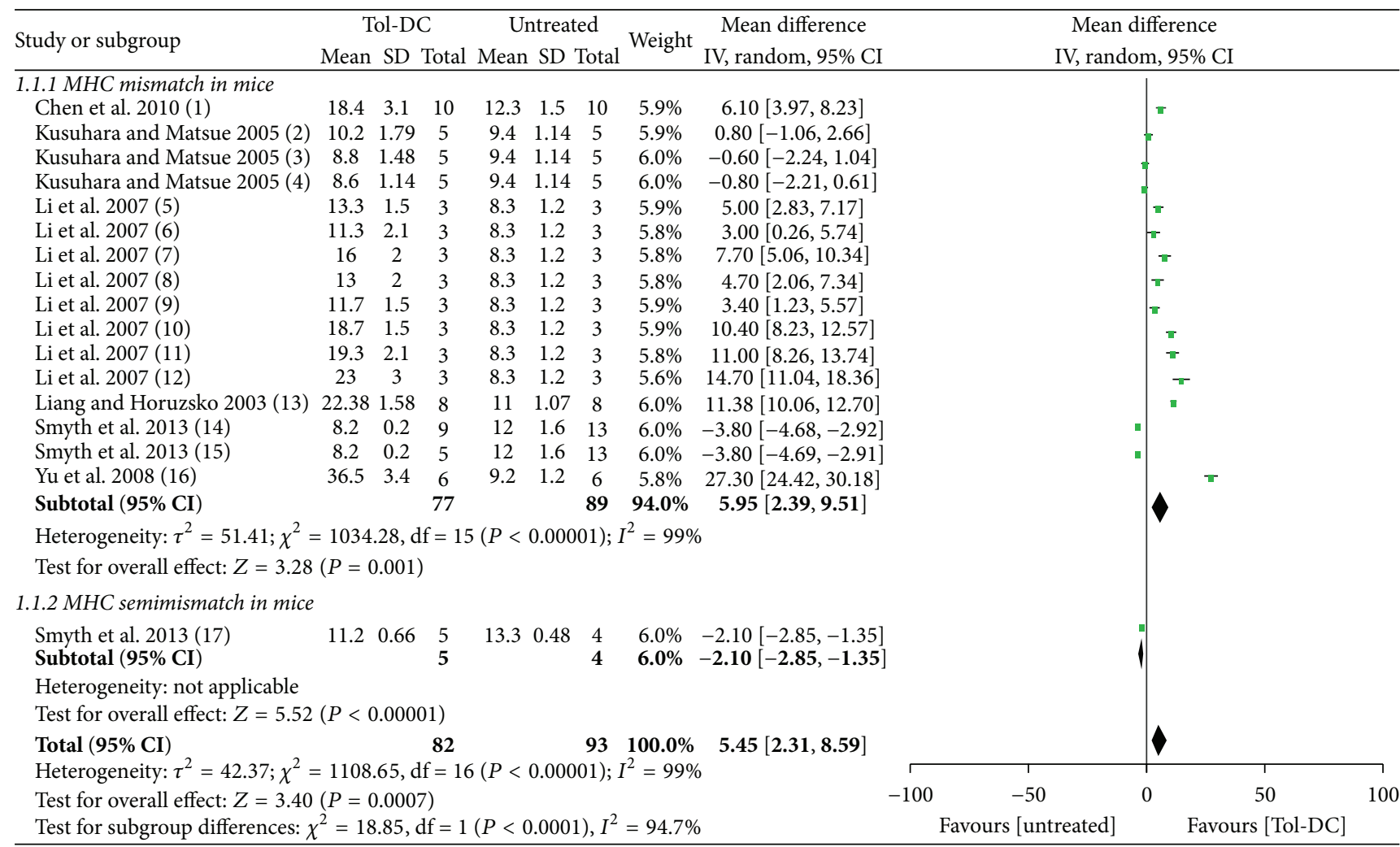

Footnotes

(1) Tetrandrine+DC

(2) CD95L-DC(donor skin derived cell line) (i.v.)

(3) CD95L-DC(donor kkin derived cell line) (i. . )

(4) CD95L-DC(donor skin derived cell line) (s...)

(5) $10 \mathrm{mg} / \mathrm{L}$ Medron+donor spleen DC

(5) $10 \mathrm{mg} / \mathrm{L}$ Medron+donor spleen DC
(6) $20 \mathrm{mg} / \mathrm{L}$ Medron+donor spleen DC

(7) $10 \mu \mathrm{g} / \mathrm{L}$ IL-10+donor spleen DC

(8) $30 \mu \mathrm{g} / \mathrm{LLL}-10+20 \mathrm{mg} / \mathrm{L}$ Medron+donor spleen DC

(9) $10 \mu \mathrm{g} / \mathrm{LLL}-10+20 \mathrm{mg} / \mathrm{L}$ Medron+donor spleen DC

(10) $10 \mu \mathrm{g} / \mathrm{L}$ LL-10+10 mg/L Medron

(12) $30 \mu \mathrm{g} / \mathrm{L}$ IL-10+10 $\mathrm{mg} / \mathrm{L}$ Medron+donor spleen DC

(13) $\mathrm{PIR}-\mathrm{B}+\mathrm{DC}$

(14) Dex+D3+LPS+DC(B6K $\left.{ }^{\mathrm{d}}\right)$

(15) $\mathrm{Dex}+\mathrm{D} 3+\mathrm{DC}\left(\mathrm{B} 6 \mathrm{~K}^{\mathrm{d}}\right)$

(17) $\mathrm{Dex}+\mathrm{D} 3+\mathrm{DC}\left(\mathrm{K}^{\mathrm{bm} 1}\right)$

(d) Skin transplantation

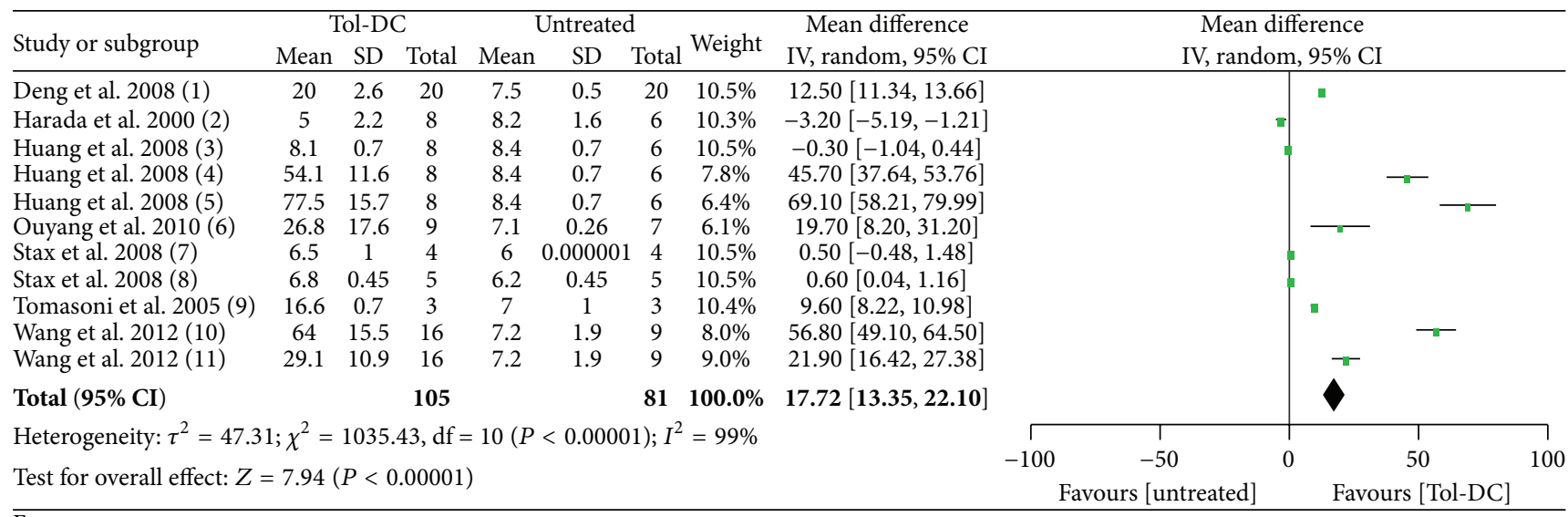

\section{Footnotes}

(2) Donor spleen DC

(3) Recipient CTLA4Ig-BMDC

(4) CTLA4Ig-DC
(5) Donor and recipient CTLA4Ig-BMDC

(6) IKK2dn-DC

(7) Dex + donor(Dark Agouti) DC
(8) Dex + donor(Brown Norway) DC
(9) dnIKK2-DC

(10) Donor antigen+CD4+recipient BMDC (11) CD4+recipient BMDC

e) Renal transplantation in rats

Figure 3: Mean difference (95\% confidence intervals) for Tol-DC infusion versus untreated groups for allografts survival in islet (a), small intestine (b), liver (c), skin (d), and renal (e) transplantation models. Except for MHC semimismatch model in skin transplantation group, all other studies involved used MHC complete mismatch models either in rats or in mice. In the footnotes, "-" before "DC" means genetic modification and "+" means substances added in the culture medium. If not specialized, DC refers to donor bone borrow DC; when injection time is involved, we take the transplantation day as day 0. i.v.: intravenous; i.p.: intraperitoneal; s.c.: subcutaneous. 


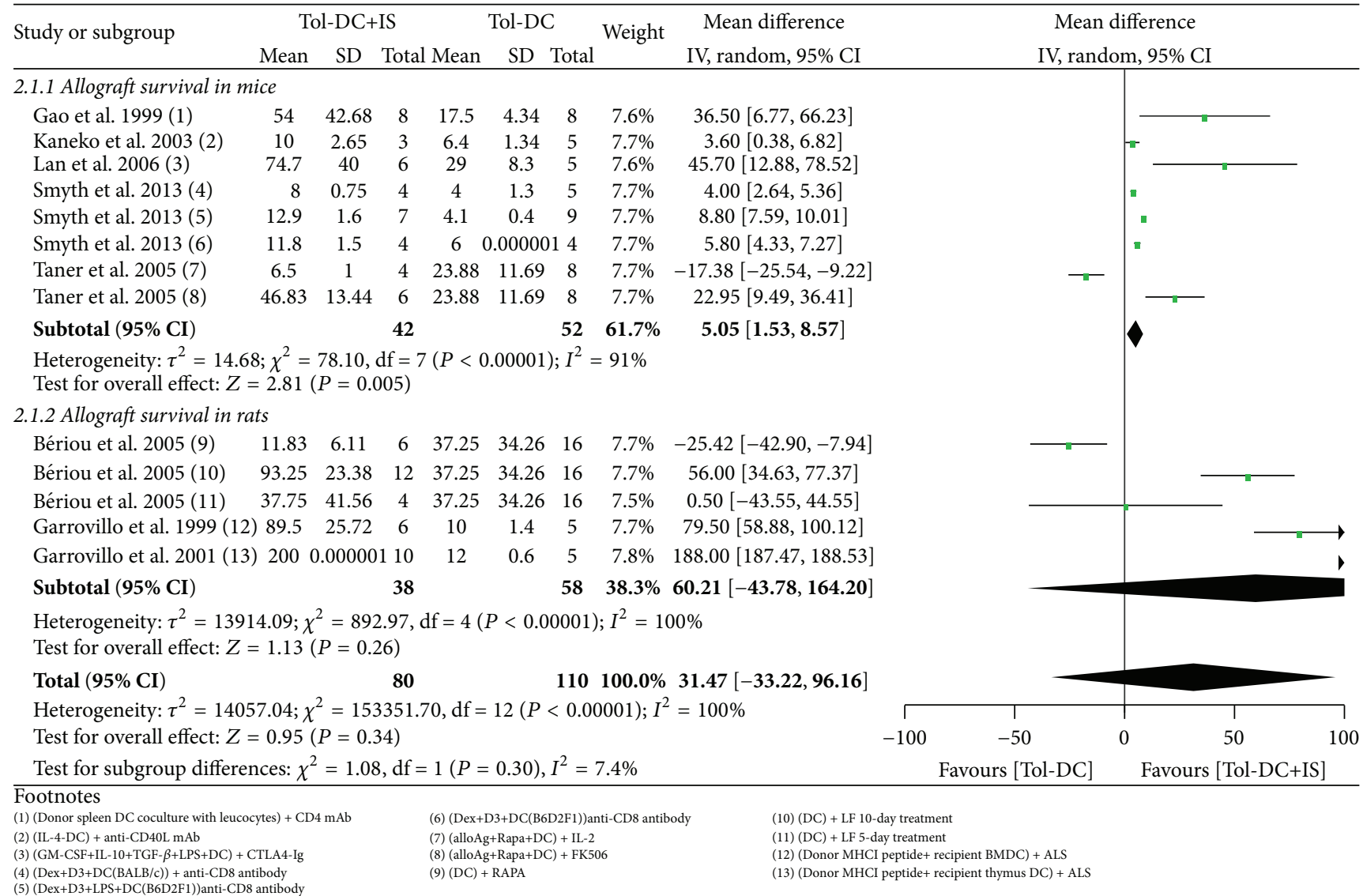

(a) Heart transplantation

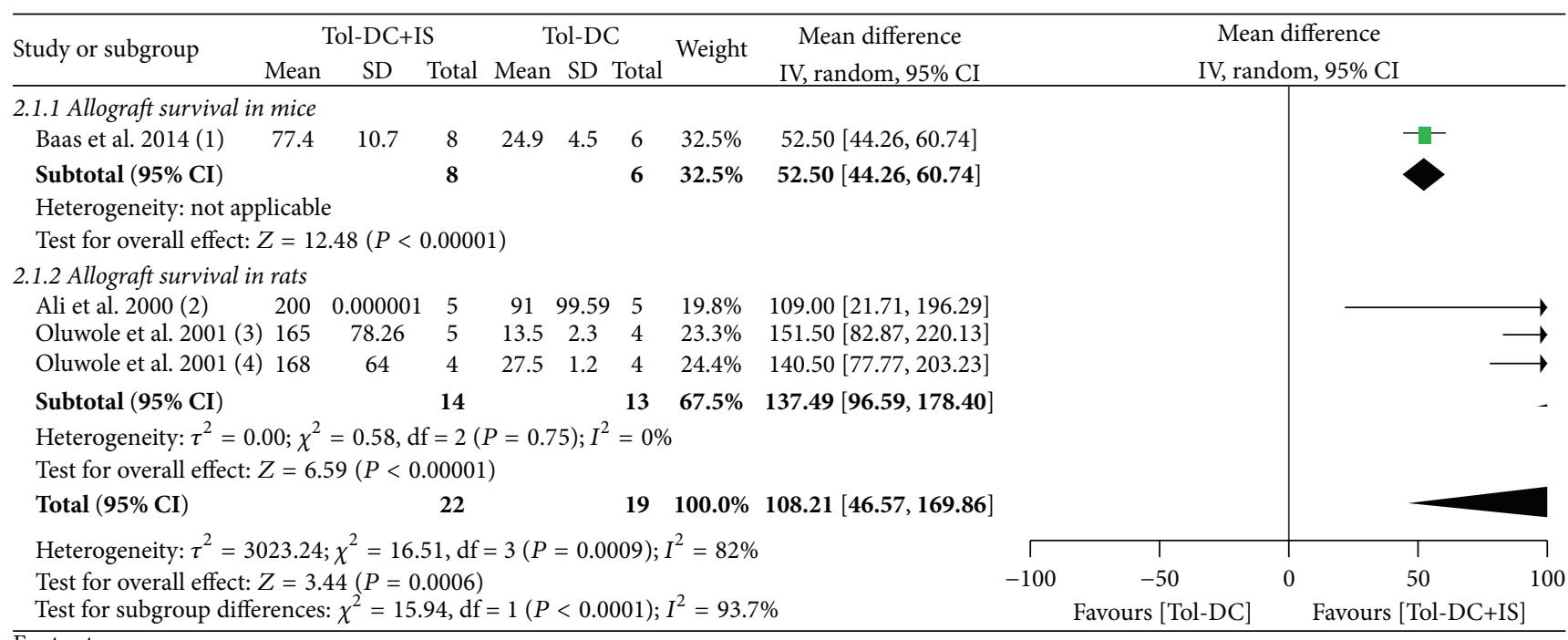

\section{Footnotes}

$\begin{array}{ll}\text { (1) }(\text { GM-CSF+recipient adherent BMDC) }+ \text { anti-CD3 } \mathrm{Ab} & \left.\text { (3) (Donor MHC I peptide+recipient BMDC }\left(2 \times 10^{6}\right)\right)+ \text { ALS } \\ \text { (2) (Donor MHC I peptide+rection }\end{array}$

(b) Islet transplantation

Figure 4: Continued. 


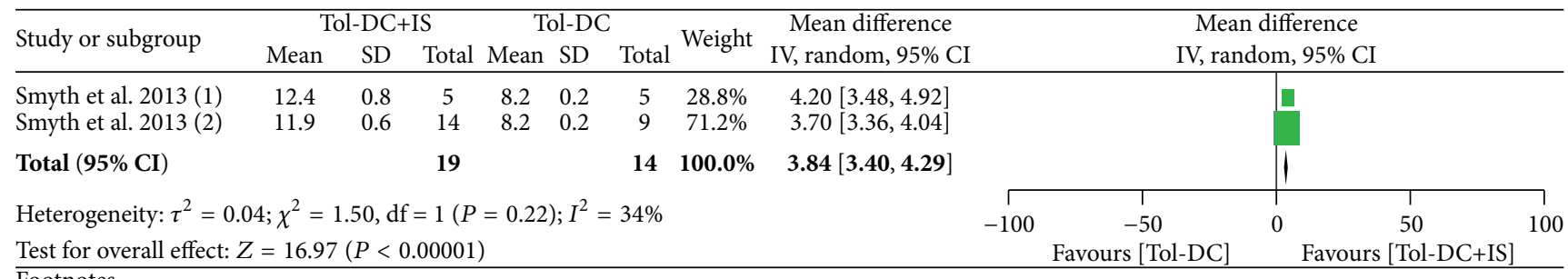

Footnotes

(1) $\left(\mathrm{Dex}+\mathrm{D} 3+\mathrm{DC}\left(\mathrm{B} 6 \mathrm{~K}^{\mathrm{d}}\right)\right)+$ anti-CD8 antibody

(1) $\left(\right.$ Dex+D3+DC $\left.\left(B 6 K^{d}\right)\right)+$ anti-CD8 antibody
(Dex+LPS+DC $\left.\left(B 6 K^{d}\right)\right)+$ anti-CD8 antibody

(c) Skin transplantation in mice

FIGURE 4: Mean difference (95\% confidence intervals) for Tol-DC in combination with IS versus Tol-DC alone for allografts survival in heart (a), islet (b), and skin (c) transplantation models. In the footnotes, “-” before "DC" means genetic modification and "+" inside the parentheses means substances added in the culture medium and "+" outside the parentheses means combined IS agents. If not specialized, DC refers to donor bone borrow DC.

3.5.3. Tol-DCs + IS versus IS Alone. In rats, Tol-DCs + IS led to better outcomes than IS alone in the survival of islet allografts, but not of heart, skin, or small intestine allografts, whereas in mice, Tol-DCs + IS were not significantly better than IS alone in prolonging the survival of heart or skin allografts (Table 3 and Figure 5). In three studies, the survival of mouse islets, rat liver, and rat kidneys was extended for significantly longer with Tol-DCs + IS than with IS alone [1618].

3.5.4. Subgroup Analysis. All of the mice used in the included studies were inbred strains, while the rats used in the liver, kidney, and small intestine studies included both inbred strains and closed colony randomly bred animals. A subgroup analysis of the inbred strains and closed colonies revealed similarly prolonged survival times in the kidney and small intestine transplantation models, and the merged results were identical. In the liver transplantation model, despite negative merged result (28.98 days, -11.16 to 69.12 ) in closed colony, we tended to take it as positive because of positive results of both included studies, then identical to inbred strains (Figure 6). Therefore, no heterogeneity in allograft survival was observed in the inbred strains and closed colony animals.

\section{Discussion}

The current overview included a total of 61 articles (47 studies from six systematic reviews and 14 primary studies) dissecting the efficacy of adoptive transfusion of Tol-DCs with or without IS drugs in promoting the survival of heart, liver, kidney, small intestine, skin, and islet allografts in animals. TolDC therapy prolonged allograft survival to varying extents in all except the islet transplantation models. Moreover, TolDC combined with IS drug therapy further prolonged the survival of heart, skin, and islet allografts in mice, but not of heart allografts in rats. Compared with IS drugs alone, TolDC + IS therapy extended islet allograft survival in rats but failed to influence the survival of skin, small intestine, and heart allografts in rats or of heart and skin allografts in mice (Table 3). Although three articles reported that Tol-DC + IS therapy had better outcomes than IS alone in the mouse islet, rat liver, and kidney transplantation models, the evidence was based on single sets of data and we therefore did not include the results in our discussion. In addition, we did not directly compare Tol-DC and IS single therapies because most of the IS drugs have long histories of clinical use, whereas Tol-DC therapy has not yet been standardized and protocol differences undoubtedly affected the outcomes of the studies included here [10-15]. Comparisons of outcomes with single versus combination Tol-DC and IS therapy suggest that IS drugs have advantages over Tol-DCs. Our meta-analysis also shows that the efficacy of Tol-DC and Tol-DC + IS therapy varied with the transplantation model in both mice and rats, presumably reflecting the diversity of immune environments, organ-specific responses, and therapeutic protocols. Indeed, the severity and acuteness of rejection have been reported to vary for different grafts within a single organism, indicating organ-specific immune responses [75]. Moreover, in one transplantation model, the outcomes were different in rats and mice, suggesting species-specific responses to Tol-DC therapy.

4.1. Limitations. The following limitations of this overview are noted. (1) The studies used different strains of rats and mice. Gene expression in primary immunocytes varies greatly across inbred mouse strains, suggesting that the same Tol-DC therapy may have variable efficacy in different strains [76]. (2) The Tol-DC modification protocols and organ donor/recipient strain derivation differed among the studies. Thus, Tol-DCs with the same modification gave different outcomes depending on the transplanted organ and the donor/recipient combinations [54, 74, 77]. Additionally, different gene modifications, drugs, cytokines, and culture media can induce Tol-DCs with immature, mature, or semimature phenotypes. Immature DCs are conventionally considered to be tolerogenic and mature DCs to be immunogenic. However, immature Tol-DCs are not always superior to mature Tol-DCs in terms of allograft survival $[38,78]$. (3) The studies differed in Tol-DC injection time, route, dose, and frequency. These factors influence Tol-DC efficacy to variable extents $[37,40,65]$, presumably by affecting the distribution, maintenance, and homing of Tol-DCs $[79,80]$. 


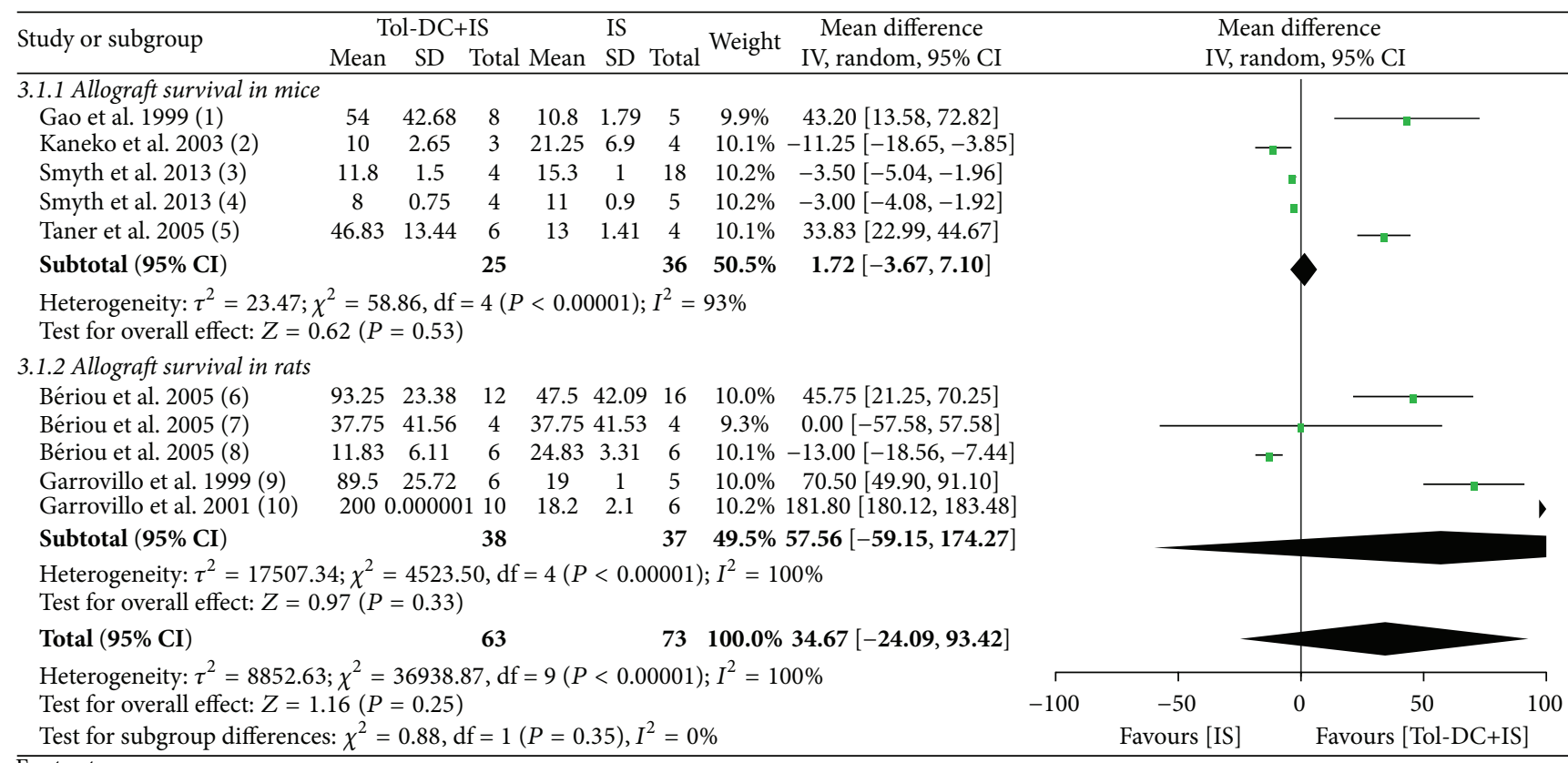

Footnotes

(1) (Donor spleen DC coculture with leucocytes) $+\mathrm{CD} 4 \mathrm{mAb}$

(2) (IL-4-DC) + anti-CD40L mAb

(3) $(\mathrm{Dex}+\mathrm{D} 3+\mathrm{DC}(\mathrm{B} 6 \mathrm{D} 2 \mathrm{~F} 1))$ anti-CD8 antibody

(4) $($ Dex $+D 3+D C(B A L B / c))+$ anti-CD8 antibody

\begin{abstract}
(5) $($ alloAg+Rapa+DC) + FK506 (6) (DC) + LF 10-day treatment (7) (DC) + LF 5-day treatment
\end{abstract}

(a) Heart transplantation

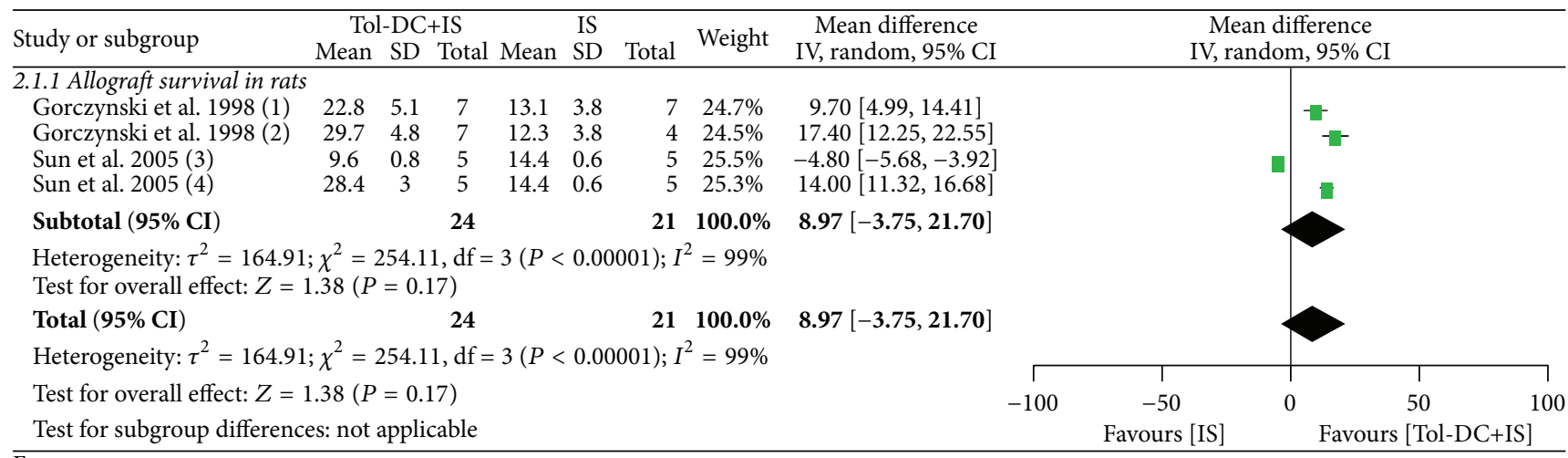

\section{Footnotes}

(1) (Donor BMDC) + CSA+anti-CD 54+anti- $\alpha_{L_{1}} \quad$ (3) (Mature BMDC) + FK506

(2) (Donor BMDC) + CsA tanti- $\alpha_{4} \quad$ (4) (iBMDC) + FK506

(b) Small intestine transplantation in rats

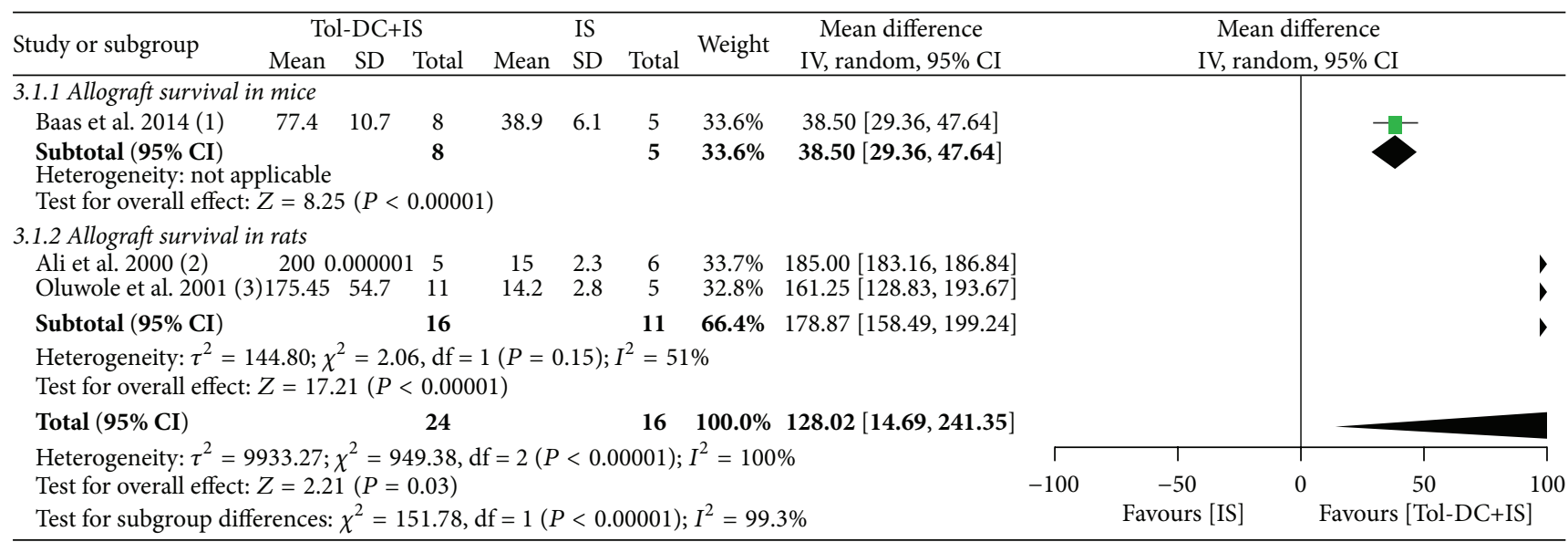

\section{Footnotes}

(1) (GM-CSF+recipient adherent BMDC) + anti-CD3 Ab

(2) (Donor MHC I peptide+recipient BMDC) + ALS

(3) (Donor MHC I peptide+recipient $\left.\operatorname{BMDC}\left(1 \times 10^{6}\right)\right)+$ ALS 


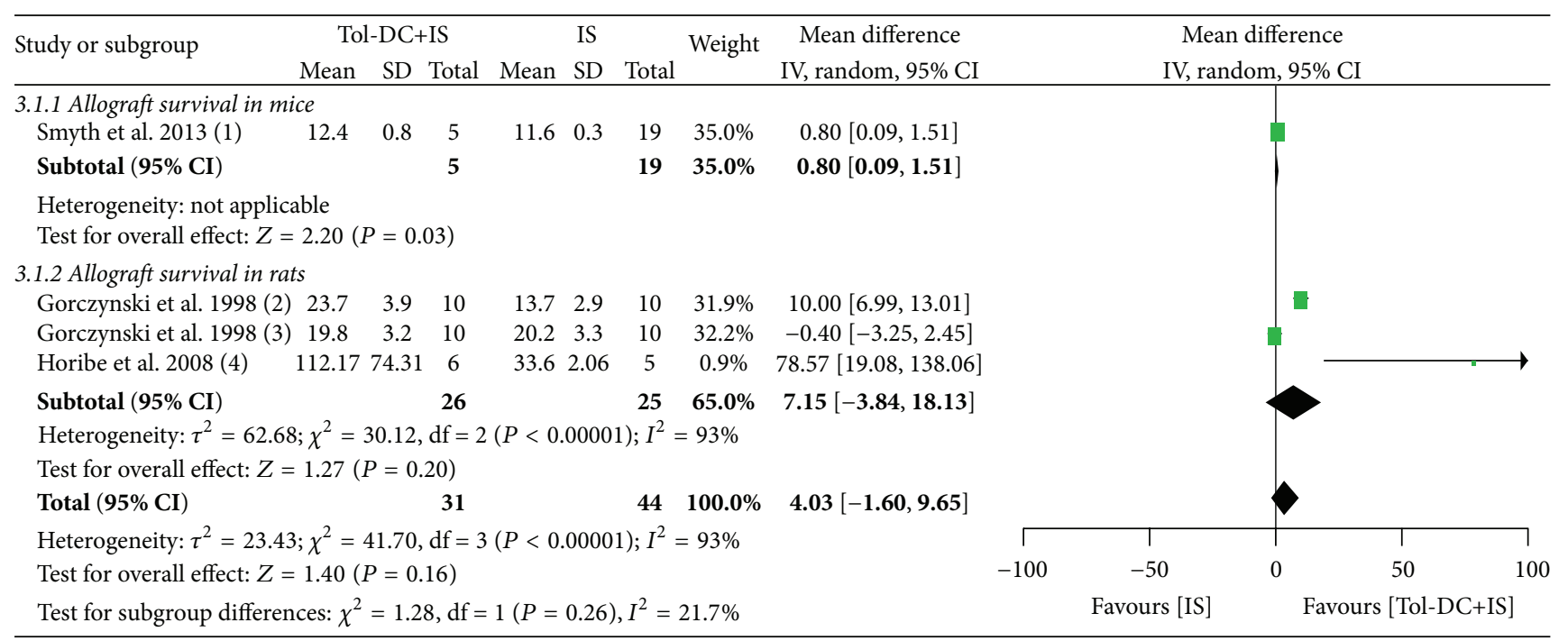

\section{Footnotes}

(1) $\left(\right.$ Dex $\left.+\mathrm{D} 3+\mathrm{DC}\left(\mathrm{B} 6 \mathrm{~K}^{\mathrm{d}}\right)\right)+$ anti-CD8 antibody

(2) (Donor BMDC) + CsA + anti- $\alpha 4$

(3) (Donor BMDC) + CsA+anti-CD $54+$ anti- $\alpha_{\mathrm{L}}$

(4) (Rapa+donor Ag+recipient BMDC) + ALS

(d) Skin transplantation

FIgURE 5: Mean difference (95\% confidence intervals) for Tol-DC in combination with IS versus IS alone for allografts survival in heart (a), small intestine (b), islet (c), and skin (d) transplantation models. Rats used in study Gorczynski 1998 [8] in small intestine and skin models were MHC semimismatch. In the footnotes, "-" before "DC" means genetic modification and "+" inside the parentheses means substances added in the culture medium and "+" outside the parentheses means combined IS agents. If not specialized, DC refers to donor bone borrow DC.

(4) The type of IS drug and the dose, time, and frequency of drug injection also differed considerably among the studies. (5) The statistical heterogeneity of the meta-analysis was very large for all transplantation models.

4.2. Clinical and Preclinical Implications. Our meta-analysis suggests that infusion of Tol-DCs alone is able to promote survival of allografts. However, there are currently no standardized protocols for the modification or application of TolDCs. To date, clinical experience with Tol-DCs is limited to a phase I trial of autologous Tol-DCs for type I diabetes, rheumatoid arthritis and refractory Crohn's disease, and an ongoing safety trial of autologous Tol-DCs for kidney transplantation [4-7]. Nevertheless, our results indicate that a number of problems must be solved before Tol-DC therapy successfully moves from bench to bedside. For instance, standardized protocols must be established for the modification and dose of Tol-DCs; the time, frequency, and route of injection; and the type of IS drugs to be administered in combination. Considering that Tol-DC efficacy may be organ-specific, the therapeutic protocol may also need to be tailored to the transplanted organ. Although Tol-DC therapy did not give better outcomes than IS therapy or show synergy with IS drugs, Tol-DC therapy does have advantages over drug therapy. First, Tol-DCs are generally infused before transplantation, and since they exert their effect at the very earliest stages of the immune response, they are very likely to inhibit hyperacute rejection. Second, Tol-DCs are likely to induce tolerance or prolong allograft survival without impairing the recipient's immune defense against other antigens. Third, the studies included in this overview did not administer IS drugs continuously. Therefore, TolDC therapy may allow IS drug use to be reduced, thus decreasing their toxicity and improving the recipients' quality of life, which is particularly important for IS-sensitive and IStolerant recipients. Notably, tacrolimus has been reported to inhibit the functions of Tol-DCs in mice [81], suggesting that further preclinical studies of Tol-DC and drug combinations are needed.

Our results indicate that Tol-DC efficacy may be speciesspecific, suggesting that studies in primates will be more clinically relevant. A kidney transplantation model has been successfully established in rhesus macaques and infusion of donor-derived Tol-DCs in combination with IS prolonged allograft survival [82]. This nonhuman primate model will help to translate research findings from animals to the clinic.

\section{Competing Interests}

All authors declared no competing interests.

\section{Acknowledgments}

This work was financially supported by 2013 program of Key Laboratory of National Health and Family Planning Commission and National Basic Research Program of China 


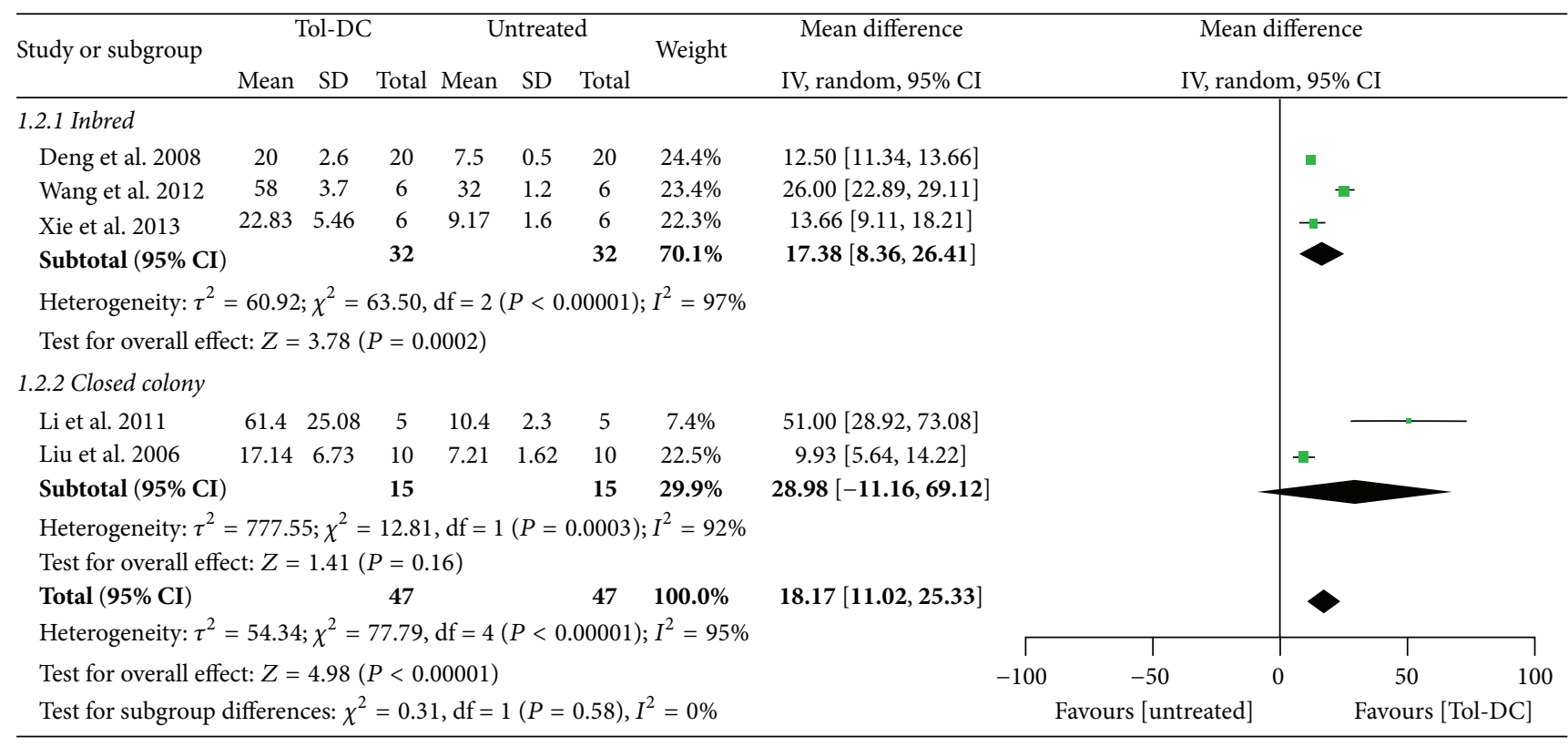

(a) Liver transplantation in rats

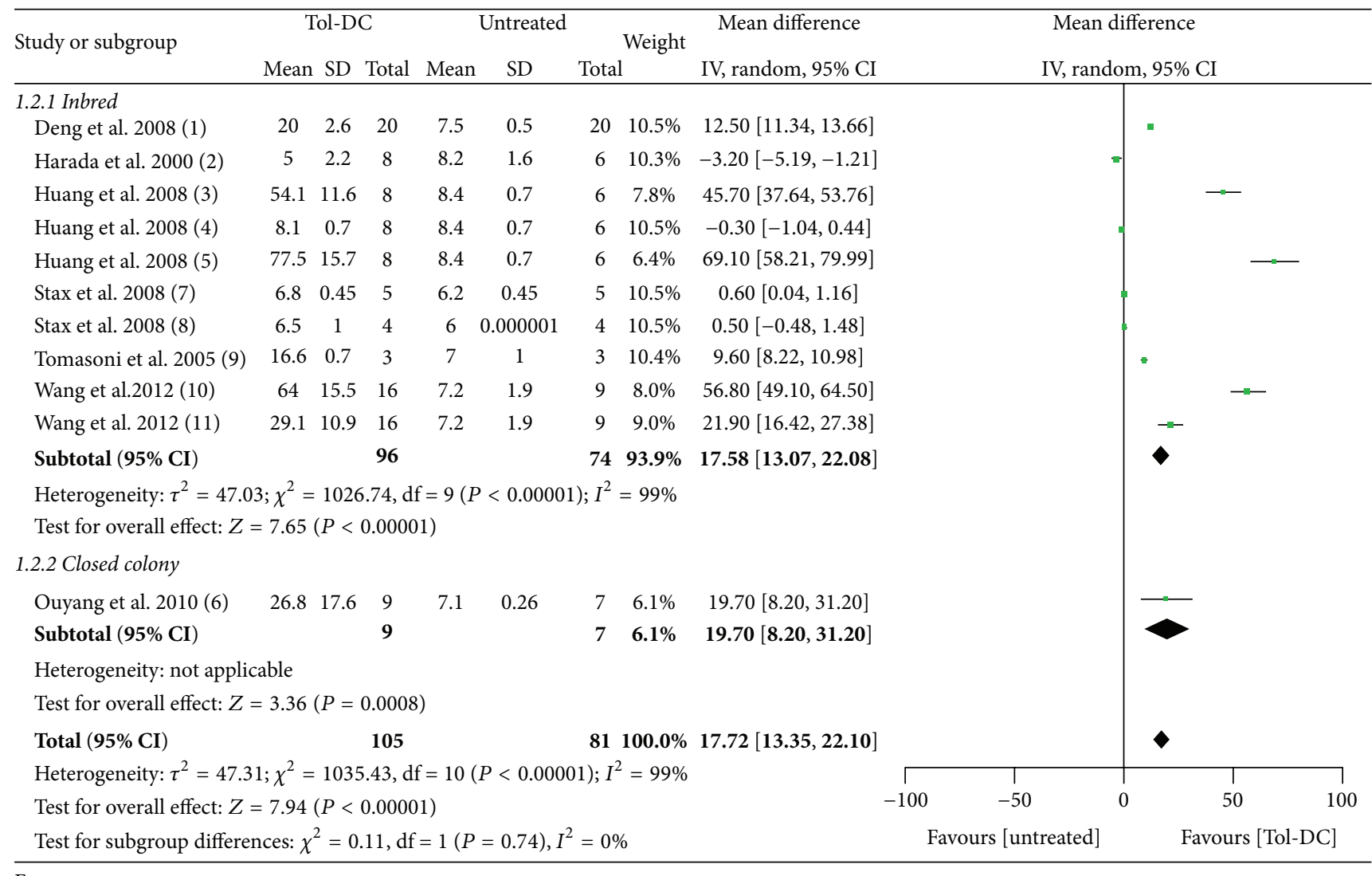

\section{Footnotes}
(1) IL-10+DC
(2) Donor spleen DC
(3) Recipient CTLA4Ig-BMDC
(4) CTLA4Ig-DC
(5) Donor and recipient CTLA4Ig-BMDC
(7) Dex+donor(Brown Norway) DC
(8) Dex+donor(Dark Agouti) DC
(9) dnIKK2-DC
(10) Donor antigen+CD4+recipient BMDC
(11) CD4+recipient BMDC

(6) IKK2dn-DC (b) Renal transplantation in rats

Figure 6: Continued. 


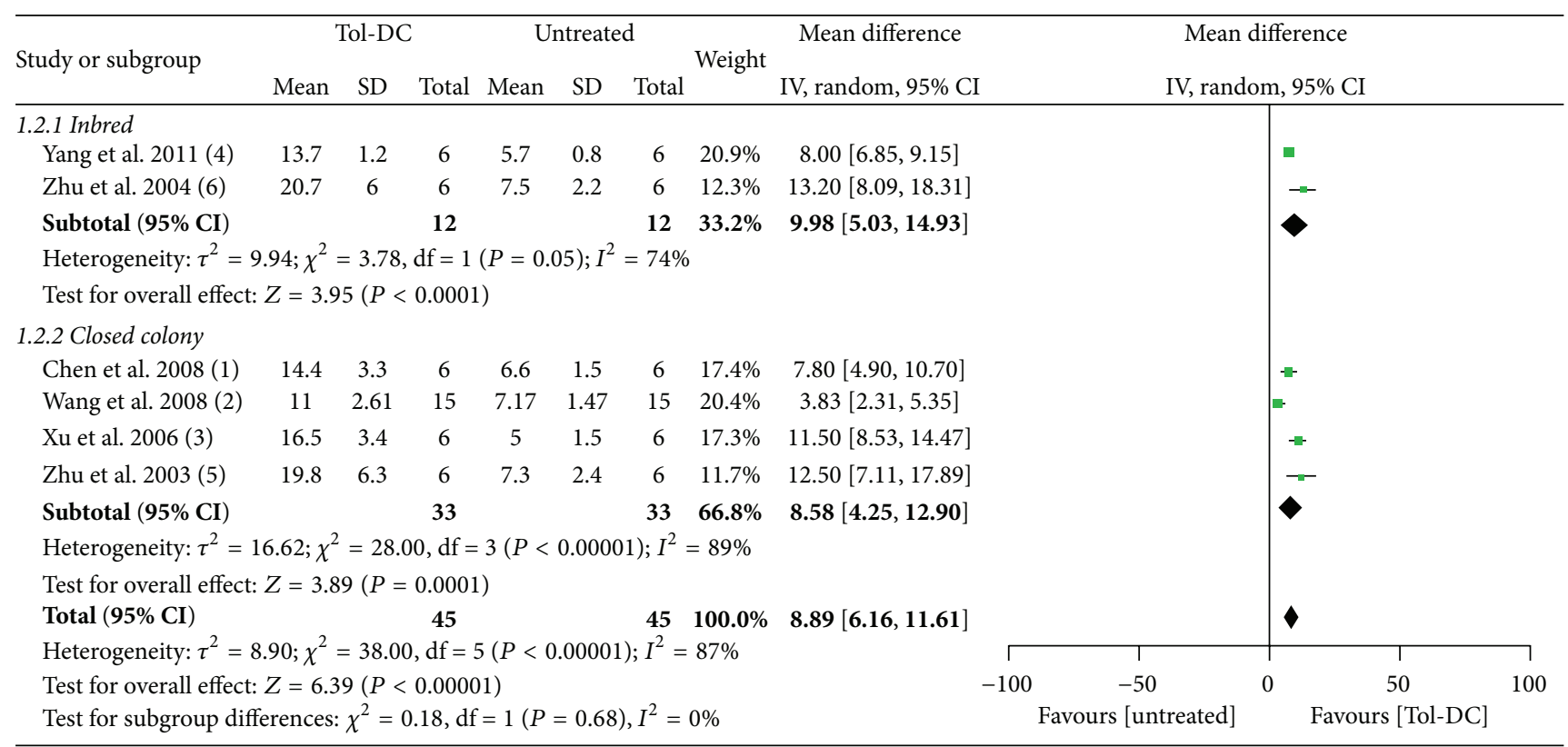

Footnotes
(1) Triptolide+DC
(2) iBMDC
(3) si-IL-12 p35-DC
(4) LPS+si-MyD88-DC
(5) Donor spleen IL10-DC
(6) IL10-DC

(c) Small intestine transplantation in rats

FiguRE 6: Mean difference (95\% confidence intervals) for subgroups of inbred and closed colony rats for allografts survival in liver (a), renal (b), and small intestine (c) transplantation models. All mice and rats in other models are inbred.

no. 2009CB522401 and by the Natural Science Foundation of China (NSFC) nos. 81270552 and 81273255.

\section{References}

[1] R. M. Steinman and Z. A. Cohn, "Identification of a novel cell type in peripheral lymphoid organs of mice. I. Morphology, quantitation, tissue distribution," Journal of Experimental Medicine, vol. 137, no. 5, pp. 1142-1162, 1973.

[2] P. W. Kantoff, C. S. Higano, N. D. Shore et al., "SipuleucelT immunotherapy for castration-resistant prostate cancer," The New England Journal of Medicine, vol. 363, no. 5, pp. 411-422, 2010.

[3] N. Cools, A. Petrizzo, E. Smits et al., "Dendritic cells in the pathogenesis and treatment of human diseases: a Janus Bifrons?” Immunotherapy, vol. 3, no. 10, pp. 1203-1222, 2011.

[4] H. Benham, H. J. Nel, S. C. Law et al., "Citrullinated peptide dendritic cell immunotherapy in HLA risk genotype-positive rheumatoid arthritis patients," Science Translational Medicine, vol. 7, no. 290, Article ID 290ra87, 2015.

[5] A. Jauregui-Amezaga, R. Cabezón, A. Ramírez-Morros et al., "Intraperitoneal administration of autologous tolerogenic dendritic cells for refractory crohn's disease: a phase I study," Journal of Crohn's and Colitis, vol. 9, no. 12, pp. 1071-1078, 2015.

[6] N. Giannoukakis, B. Phillips, D. Finegold, J. Harnaha, and M. Trucco, "Phase I (safety) study of autologous tolerogenic dendritic cells in type 1 diabetic patients," Diabetes Care, vol. 34, no. 9, pp. 2026-2032, 2011.
[7] A. Moreau, E. Varey, L. Bouchet-Delbos, and M.-C. Cuturi, "Cell therapy using tolerogenic dendritic cells in transplantation," Transplantation Research, vol. 1, no. 1, article 13, 2012.

[8] R. M. Gorczynski, X. M. Fu, T. Issekutz, and Z. Cohen, "Differential regulation of rejection of small intestinal and skin allografts in rats by injection of antibodies to ICAM-1 or the integrins $\alpha 4, \alpha(\mathrm{L})$, or $\beta 2$," Cellular Immunology, vol. 184, no. 1 , pp. 74-82, 1998.

[9] B. J. Shea, C. Hamel, G. A. Wells et al., "AMSTAR is a reliable and valid measurement tool to assess the methodological quality of systematic reviews," Journal of Clinical Epidemiology, vol. 62, no. 10, pp. 1013-1020, 2009.

[10] W. Wu, J. Shan, Y. Li et al., "Adoptive transfusion of tolerance dendritic cells prolongs the survival of cardiac allograft: a systematic review of 44 basic studies in mice," Journal of Evidence-Based Medicine, vol. 5, no. 3, pp. 139-153, 2012.

[11] G. Sun, J. Shan, Y. Li et al., "Adoptive infusion of tolerogenic dendritic cells prolongs the survival of pancreatic islet allografts: a systematic review of 13 mouse and rat studies," PLOS ONE, vol. 7, no. 12, Article ID e52096, 2012.

[12] M. J. Xia, J. Shan, Y. P. Li et al., "Adoptive transfusion of tolerogenic dendritic cells prolongs the survival of liver allograft: a systematic review," Journal of Evidence-Based Medicine, vol. 7, no. 2, pp. 135-146, 2014.

[13] M. J. Xia, J. Shan, Y. P. Li et al., "Adoptive transfusion of tolerant dendritic cells prolong the survival of renal allografts: a systematic review," Journal of Evidence-Based Medicine, vol. 6, no. 4, pp. 250-264, 2013.

[14] Y. Zhou, J. Shan, Y. Li et al., "Adoptive transfusion of tolerance dendritic cells prolongs the survival of skin allografts in mice: 
a systematic review," Journal of Evidence-Based Medicine, vol. 6, no. 2, pp. 90-103, 2013.

[15] G. Sun, J. Shan, Y. Li et al., "Adoptive infusion of tolerance dendritic cells prolongs survival of small intestine allografts in rats: systematic review and meta-analysis," Journal of EvidenceBased Medicine, vol. 6, no. 3, pp. 185-196, 2013.

[16] G.-Y. Wang, Y. Yang, H. Li et al., "Rapamycin combined with donor immature dendritic cells promotes liver allograft survival in association with CD $4+\mathrm{CD} 25+$ Foxp $3+$ regulatory $\mathrm{T}$ cell expansion," Hepatology Research, vol. 42, no. 2, pp. 192-202, 2012.

[17] H. Harada, H. Ishikura, I. Nakagawa et al., "Abortive alloantigen presentation by donor dendritic cells leads to donor-specific tolerance: a study with a preoperative CTLA4Ig inoculation," Urological Research, vol. 28, no. 1, pp. 69-74, 2000.

[18] M. C. Baas, C. Kuhn, F. Valette et al., "Combining autologous dendritic cell therapy with CD3 antibodies promotes regulatory T cells and permanent Islet allograft acceptance," Journal of Immunology, vol. 193, no. 9, pp. 4696-4703, 2014.

[19] M. Zhu, M.-F. Wei, F. Liu, H.-F. Shi, and G. Wang, "Interleukin10 modified dendritic cells induce allo-hyporesponsiveness and prolong small intestine allograft survival," World Journal of Gastroenterology, vol. 9, no. 11, pp. 2509-2512, 2003.

[20] M. Zhu, M. F. Wei, F. Liu, H. F. Shi, G. Wang, and S. Chen, "Allogeneic T-cell apoptosis induced by interleukin10-modified dendritic cells: a mechanism of prolongation of intestine allograft survival?" Transplantation Proceedings, vol. 36, no. 8, pp. 2436-2437, 2004.

[21] D. Sheng Sun, H. Iwagaki, M. Ozaki et al., "Prolonged survival of donor-specific rat intestinal allograft by administration of bone-marrow-derived immature dendritic cells," Transplant Immunology, vol. 14, no. 1, pp. 17-20, 2005.

[22] H. Xu, T. Chen, H. Q. Wang, M. J. Ji, X. Zhu, and W. X. Wu, "Prolongation of rat intestinal allograft survival by administration of donor interleukin-12 p35-silenced bone marrow-derived dendritic cells," Transplantation Proceedings, vol. 38, no. 5, pp. 1561-1563, 2006.

[23] T. Chen, H. Xu, H. Q. Wang et al., "Prolongation of rat intestinal allograft survival by administration of triptolide-modified donor bone marrow-derived dendritic cells," Transplantation Proceedings, vol. 40, no. 10, pp. 3711-3713, 2008.

[24] H. Q. Wang, T. Chen, H. Xu et al., "Combination of immature dendritic cells and anti-CD40L monoclonal antibody induces immune tolerance of intestina allograft in rats," World Chinese Journal of Digestology, 2008.

[25] X.-J. Yang, S. Meng, Z. Chun-Fu, H. Jiang, and W.-X. Wu, "Semi-mature MyD88-silenced bone marrow dendritic cells prolong the allograft survival in a rat model of intestinal transplantation," Chinese Medical Journal, vol. 124, no. 2, pp. 268-272, 2011.

[26] F. Fu, Y. Li, S. Qian et al., "Costimulatory molecule-deficient dendritic cell progenitors (MHC class II+, CD80dim, CD86) prolong cardiac allograft survival in nonimmunosuppressed recipients," Transplantation, vol. 62, no. 5, pp. 659-665, 1996.

[27] L. Lina, W. Li, F. Fu et al., "Blockade of the CD40-CD40 ligand pathway potentiates the capacity of donor-derived dendritic cell progenitors to induce long-term cardiac allograft survival," Transplantation, vol. 64, no. 12, pp. 1808-1815, 1997.

[28] J.-X. Gao, J. Madrenas, W. Zeng et al., "CD40-deficient dendritic cells producing interleukin-10, but not interleukin-12, induce T-cell hyporesponsiveness in vitro and prevent acute allograft rejection," Immunology, vol. 98, no. 2, pp. 159-170, 1999.
[29] W.-P. Min, R. Gorczynski, X.-Y. Huang et al., "Dendritic cells genetically engineered to express Fas ligand induce donorspecific hyporesponsiveness and prolong allograft survival," Journal of Immunology, vol. 164, no. 1, pp. 161-167, 2000.

[30] C. A. Bonham, L. Peng, X. Liang et al., "Marked prolongation of cardiac allograft survival by dendritic cells genetically engineered with NF- $\kappa$ B oligodeoxyribonucleotide decoys and adenoviral vectors encoding CTLA4-Ig," Journal of Immunology, vol. 169, no. 6, pp. 3382-3391, 2002.

[31] B. Li, Y. Koide, M. Uchijima, Y. Ohtawara, and K. Fujita, "Pretreatment of recipients with mitomycin-C-treated dendritic cells induces significant prolongation of cardiac allograft survival in mice," Transplantation Proceedings, vol. 34, no. 8, pp. 3426-3428, 2002.

[32] T. Takayama, K. Kaneko, A. E. Morelli, W. Li, H. Tahara, and A. W. Thomson, "Retroviral delivery of transforming growth factor- $\beta 1$ to myeloid dendritic cells: inhibition of T-cell priming ability and influence on allograft survival," Transplantation, vol. 74, no. 1, pp. 112-119, 2002.

[33] C.-H. Han, H.-F. Li, Y.-X. Wang et al., "The influence of mycophenolate mofetil upon the maturation and allostimulatory activity of cultured dendritic cell progenitors and the effects of tolerance induction in allograft recipients," Zhonghua Yi Xue Za Zhi, vol. 85, no. 19, pp. 1327-1332, 2005.

[34] Y. Y. Lan, Z. Wang, G. Raimondi et al., “'Alternatively activated' dendritic cells preferentially secrete IL-10, expand Foxp $3^{+} \mathrm{CD} 4^{+}$ $\mathrm{T}$ cells, and induce long-term organ allograft survival in combination with CTLA4-Ig," Journal of Immunology, vol. 177, no. 9, pp. 5868-5877, 2006.

[35] G. Su, W.-Z. Zhao, J.-J. Chen et al., "Pretreatment of donor dendritic cells with NBD-peptide prolongs mouse cardiac allograft survival," Journal of Southern Medical University, vol. 28, no. 9, pp. 1562-1567, 2008.

[36] K. Kaneko, Z. Wang, S. H. Kim, A. E. Morelli, P. D. Robbins, and A. W. Thomson, "Dendritic cells genetically engineered to express IL-4 exhibit enhanced IL-12p70 production in response to CD40 ligation and accelerate organ allograft rejection," Gene Therapy, vol. 10, no. 2, pp. 143-152, 2003.

[37] M. Zhang, Q. Wang, Y. Liu et al., "Effective induction of immune tolerance by portal venous infusion with IL-10 gene-modified immature dendritic cells leading to prolongation of allograft survival," Journal of Molecular Medicine, vol. 82, no. 4, pp. 240249, 2004.

[38] P. J. O’Connell, W. Li, Z. Wang, S. M. Specht, A. J. Logar, and A. W. Thomson, "Immature and mature CD $8 \alpha+$ dendritic cells prolong the survival of vascularized heart allografts," Journal of Immunology, vol. 168, no. 1, pp. 143-154, 2002.

[39] H. Hikawa, M. T. Lotze, and W. D. Rosenblum, "Induction of peripheral tolerance by local delivery of dendritic cell progenitors to cardiac allografts in a murine heterotopic heart transplantation model," General Thoracic and Cardiovascular Surgery, vol. 55, no. 8, pp. 307-314, 2007.

[40] T. Taner, H. Hackstein, Z. Wang, A. E. Morelli, and A. W. Thomson, "Rapamycin-treated, alloantigen-pulsed host dendritic cells induce Ag-specific T cell regulation and prolong graft survival," American Journal of Transplantation, vol. 5, no. 2, pp. 228-236, 2005.

[41] X. Liang, Z. Chen, J. J. Fung, S. Qian, and L. Lu, "Regulatory dendritic cells modulate immune responses via induction of T-cell apoptotic death," Microsurgery, vol. 26, no. 1, pp. 21-24, 2006. 
[42] S. Liang and A. Horuzsko, "Mobilizing dendritic cells for tolerance by engagement of immune inhibitory receptors for HLA-G," Human Immunology, vol. 64, no. 11, pp. 1025-1032, 2003.

[43] M. Kusuhara and H. Matsue, "Limitations of CD95 ligandtransduced killer dendritic cells to prevent graft rejections," Experimental Dermatology, vol. 14, no. 4, pp. 273-280, 2005.

[44] X. Li, K.-F. Dou, H.-L. Liu, F.-Q. Zhang, and L. Cai, "Immune tolerance induced by IL-10 and methylprednisolone modified dendritic cells in vitro," Chinese Journal of Cellular and Molecular Immunology, vol. 23, no. 5, pp. 436-438, 2007.

[45] Q. Wang, Y.-Z. Peng, Y.-T. Wang et al., "Study on the induction of skin transplantation tolerance against rejection in mice by third-party dendritic cells loaded with donor's antigens," Chinese Journal of Burns, vol. 23, no. 6, pp. 409-412, 2007.

[46] G. Yu, M. Fang, M. Gong et al., "Steady state dendritic cells with forced IDO expression induce skin allograft tolerance by upregulation of regulatory T cells," Transplant Immunology, vol. 18, no. 3, pp. 208-219, 2008.

[47] Y. Chen, H.-S. Lai, B.-L. Chiang, S.-H. Tseng, and W.-J. Chen, "Tetrandrine attenuates dendritic cell-mediated alloimmune responses and prolongs graft survival in mice," Planta Medica, vol. 76, no. 13, pp. 1424-1430, 2010.

[48] S.-X. Deng, J.-L. Li, and Y. Ma, "In vivo migration and immunoprotection of interleukin-10-modified dendritic cells in rats after heterogenic simultaneous liver-kidney transplantation," Journal of Clinical Rehabilitative Tissue Engineering Research, vol. 12, no. 40, pp. 7947-7950, 2008.

[49] L. Li, S.-N. Zhang, J.-H. Ran, J. Liu, Z. Li, and L.-B. Li, "Mechanism of immune hyporesponsiveness induced by recipientderived immature dendritic cells in liver transplantation rat," Chinese Medical Sciences Journal, vol. 26, no. 1, pp. 28-35, 2011.

[50] N. Liu, T.-D. Duan, and N. Zheng, "Effects of TGF- $\beta 1$ gene modified donor dendritic cells on immune repulsion," Journal of Sichuan University (Medical Science Edition), vol. 37, no. 5, pp. 721-725, 2006.

[51] J. Xie, Y. Wang, J. Bao et al., "Immune tolerance induced by RelB short-hairpin RNA interference dendritic cells in liver transplantation," The Journal of Surgical Research, vol. 180, no. 1, pp. 169-175, 2013.

[52] S. Tomasoni, S. Aiello, L. Cassis et al., "Dendritic cells genetically engineered with adenoviral vector encoding dnIKK2 induce the formation of potent CD4+ T-regulatory cells," Transplantation, vol. 79, no. 9, pp. 1056-1061, 2005.

[53] H. Zhao, X. Wang, Y. F. Zhang et al., "Immune tolerance induced by immature dendritic cells and bone marrow transplantation in rat renal allogeneic graft model and its mechanisms," Acta Academiae Medicinae Shanghai, vol. 32, no. 1, pp. 63-66, 2005.

[54] C.-B. Huang, J. Li, G.-F. Zhang, M.-Q. Fan, and Q. Wang, "Influence of dendritic cells modified with costimulatory blocker cytotoxic T lymphocyte associated antigen-4 immunoglobulin on the survival of renal allografts," Journal of Clinical Rehabilitative Tissue Engineering Research, vol. 12, no. 31, pp. 6161-6164, 2008.

[55] A. M. Stax, K. A. Gelderman, N. Schlagwein et al., "Induction of donor-specific t-cell hyporesponsiveness using dexamethasone-treated dendritic cells in two fully mismatched rat kidney transplantation models," Transplantation, vol. 86, no. 9, pp. 1275-1282, 2008.
[56] J. Ouyang, C. Fan, D. Wen et al., "Donor antigen-loaded IKK2dn gene-modified dendritic cells prolong allograft survival," Scandinavian Journal of Immunology, vol. 71, no. 5, pp. 336-344, 2010.

[57] T. Wang, L. Xu, H. Li et al., "Immature CD4+ dendritic cells conditioned with donor kidney antigen prolong renal allograft survival in rats," Chinese Medical Journal, vol. 125, no. 14, pp. 2530-2537, 2012.

[58] E. Chaib, I. G. Brons, A. Papalois, and R. Y. Calne, "Does intrathymic injection of alloantigen-presenting cells before islet allo-transplantation prolong graft survival?" Transplant International, vol. 7, supplement 1, pp. S423-S425, 1994.

[59] A. Ali, M. Garrovillo, M.-X. Jin, M. A. Hardy, and S. F. Oluwole, "Major histocompatibility complex class I peptidepulsed host dendritic cells induce antigen-specific acquired thymic tolerance to islet cells," Transplantation, vol. 69, no. 2, pp. 221-226, 2000.

[60] R. W. O’Rourke, S.-M. Kang, J. A. Lower et al., "A dendritic cell line genetically modified to express CTLA4-Ig as a means to prolong islet allograft survival," Transplantation, vol. 69, no. 7, pp. 1440-1446, 2000.

[61] H. Zhu, W. Qiu, P. Lei et al., "IL-10 gene modified dendritic cells inhibit $\mathrm{T}$ helper type 1-mediated alloimmune responses and promote immunological tolerance in diabetes," Cellular \& Molecular Immunology, vol. 5, no. 1, pp. 41-46, 2008.

[62] D.-F. Yang, W.-H. Qiu, H.-F. Zhu et al., "CTLA4-Ig-modified dendritic cells inhibit lymphocyte-mediated alloimmune responses and prolong the islet graft survival in mice," Transplant Immunology, vol. 19, no. 3-4, pp. 197-201, 2008.

[63] Y. Heng, Y. Ma, H. Yin et al., "Adoptive transfer of FTY720treated immature BMDCs significantly prolonged cardiac allograft survival," Transplant International, vol. 23, no. 12, pp. 12591270, 2010.

[64] C. Liu, H. Chen, J. Jia, T. Hong, and C. Wang, "DCs sensitized with mPD-L1-Ig fusion protein improve the effect of heart transplantation in mice by promoting the generation of T-reg cells," Cellular Immunology, vol. 290, no. 1, pp. 169-177, 2014.

[65] G. Bériou, H. Pêche, C. Guillonneau, E. Merieau, and M.-C. Cuturi, "Donor-specific allograft tolerance by administration of recipient-derived immature dendritic cells and suboptimal immunosuppression," Transplantation, vol. 79, no. 8, pp. 969972, 2005.

[66] H. A. DePaz, O. O. Oluwole, A. O. Adeyeri et al., "Immature rat myeloid dendritic cells generated in low-dose granulocyte macrophage-colony stimulating factor prolong donor-specific rat cardiac allograft survival," Transplantation, vol. 75, no. 4, pp. 521-528, 2003.

[67] M. Garrovillo, A. Ali, and S. F. Oluwole, "Indirect allorecognition in acquired thymic tolerance: induction of donor-specific tolerance to rat cardiac allografts by allopeptide-pulsed host dendritic cells," Transplantation, vol. 68, no. 12, pp. 1827-1834, 1999.

[68] M. Garrovillo, A. Ali, H. A. Depaz et al., "Induction of transplant tolerance with immunodominant allopeptide-pulsed host lymphoid and myeloid dendritic cells," American Journal of Transplantation, vol. 1, no. 2, pp. 129-137, 2001.

[69] L. P. Jiga, S. Ehser, C. Kleist, G. Opelz, and P. Terness, "Inhibition of heart allograft rejection with mitomycin C-treated donor dendritic cells," Transplantation, vol. 83, no. 3, pp. 347-350, 2007.

[70] H. Pêche, B. Trinité, B. Martinet, and M. C. Cuturi, "Prolongation of heart allograft survival by immature dendritic 
cells generated from recipient type bone marrow progenitors," American Journal of Transplantation, vol. 5, no. 2, pp. 255-267, 2005.

[71] L. A. Smyth, K. Ratnasothy, A. Moreau et al., "Tolerogenic donor-derived dendritic cells risk sensitization in vivo owing to processing and presentation by recipient APCs," The Journal of Immunology, vol. 190, no. 9, pp. 4848-4860, 2013.

[72] E. K. Horibe, J. Sacks, J. Unadkat et al., "Rapamycinconditioned, alloantigen-pulsed dendritic cells promote indefinite survival of vascularized skin allografts in association with $\mathrm{T}$ regulatory cell expansion," Transplant Immunology, vol. 18, no. 4, pp. 307-318, 2008.

[73] G. B. Ferreira, E. van Etten, A. Verstuyf et al., "1,25Dihydroxyvitamin $\mathrm{D}_{3}$ alters murine dendritic cell behaviour in vitro and in vivo," Diabetes/Metabolism Research and Reviews, vol. 27, no. 8, pp. 933-941, 2011.

[74] O. O. Oluwole, H. A. Depaz, R. Gopinathan et al., "Indirect allorecognition in acquired thymic tolerance: induction of donor-specific permanent acceptance of rat islets by adoptive transfer of allopeptide-pulsed host myeloid and thymic dendritic cells," Diabetes, vol. 50, no. 7, pp. 1546-1552, 2001.

[75] H. Takahashi, G. Selvaggi, S. Nishida et al., "Organ-specific differences in acute rejection intensity in a multivisceral transplant," Transplantation, vol. 81, no. 2, pp. 297-299, 2006.

[76] S. Mostafavi, A. Ortiz-Lopez, M. A. Bogue et al., "Variation and genetic control of gene expression in primary immunocytes across inbred mouse strains," The Journal of Immunology, vol. 193, no. 9, pp. 4485-4496, 2014.

[77] N. Emmanouilidis, Z. Guo, Y. Dong et al., "Immunosuppressive and trafficking properties of donor splenic and bone marrow dendritic cells," Transplantation, vol. 81, no. 3, pp. 455-462, 2006.

[78] H. Dai, H. Zhu, P. Lei et al., "Programmed death-1 signaling is essential for the skin allograft protection by alternatively activated dendritic cell infusion in mice," Transplantation, vol. 88, no. 7, pp. 864-873, 2009.

[79] R. J. Creusot, S. S. Yaghoubi, P. Chang et al., "Lymphoid tissuespecific homing of bone marrow-derived dendritic cells," Blood, vol. 113, no. 26, pp. 6638-6647, 2009.

[80] H. W. Lee, S. Y. Yoon, T. D. Singh et al., “Tracking of dendritic cell migration into lymph nodes using molecular imaging with sodium iodide symporter and enhanced firefly luciferase genes," Scientific Reports, vol. 5, article 9865, 2015.

[81] Y.-R. Lee, I.-H. Yang, Y.-H. Lee et al., "Cyclosporin A and tacrolimus, but not rapamycin, inhibit MHC-restricted antigen presentation pathways in dendritic cells," Blood, vol. 105, no. 10, pp. 3951-3955, 2005.

[82] M. B. Ezzelarab, A. F. Zahorchak, L. Lu et al., "Regulatory dendritic cell infusion prolongs kidney allograft survival in nonhuman primates," American Journal of Transplantation, vol. 13, no. 8, pp. 1989-2005, 2013. 


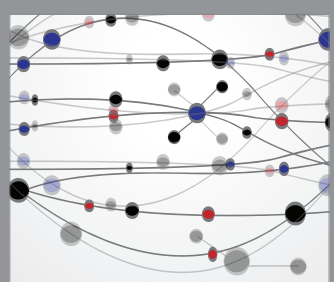

The Scientific World Journal
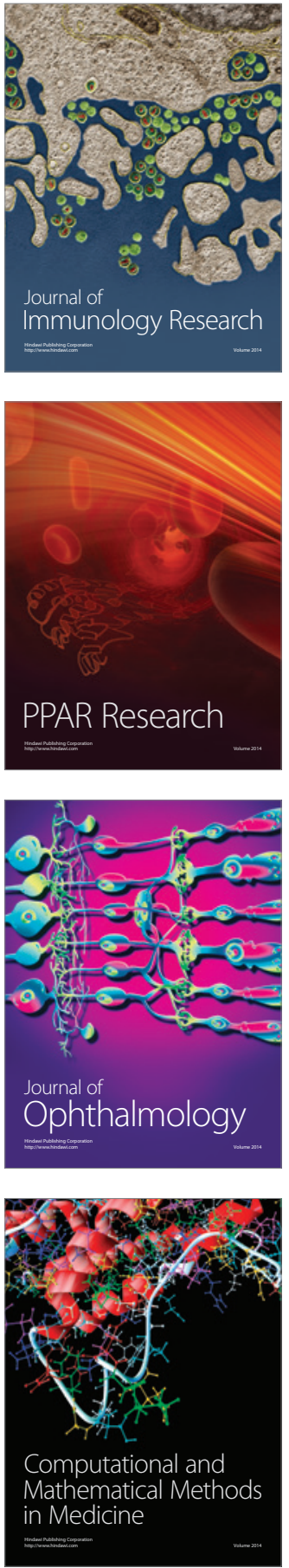

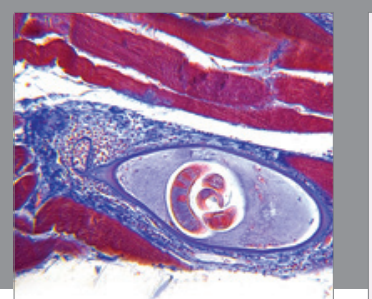

Gastroenterology Research and Practice

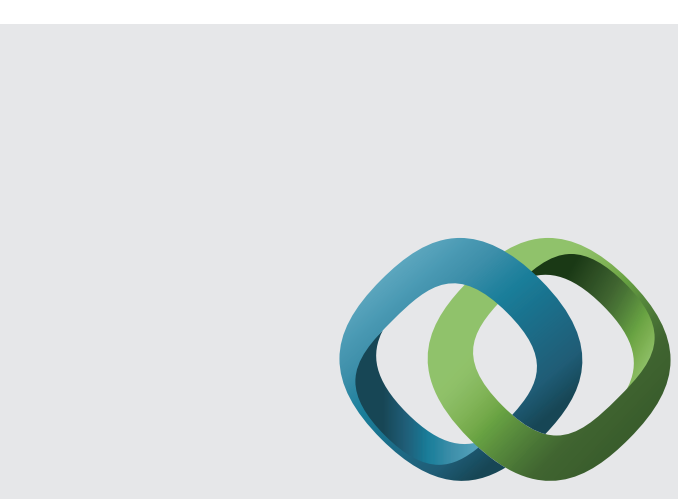

\section{Hindawi}

Submit your manuscripts at

http://www.hindawi.com
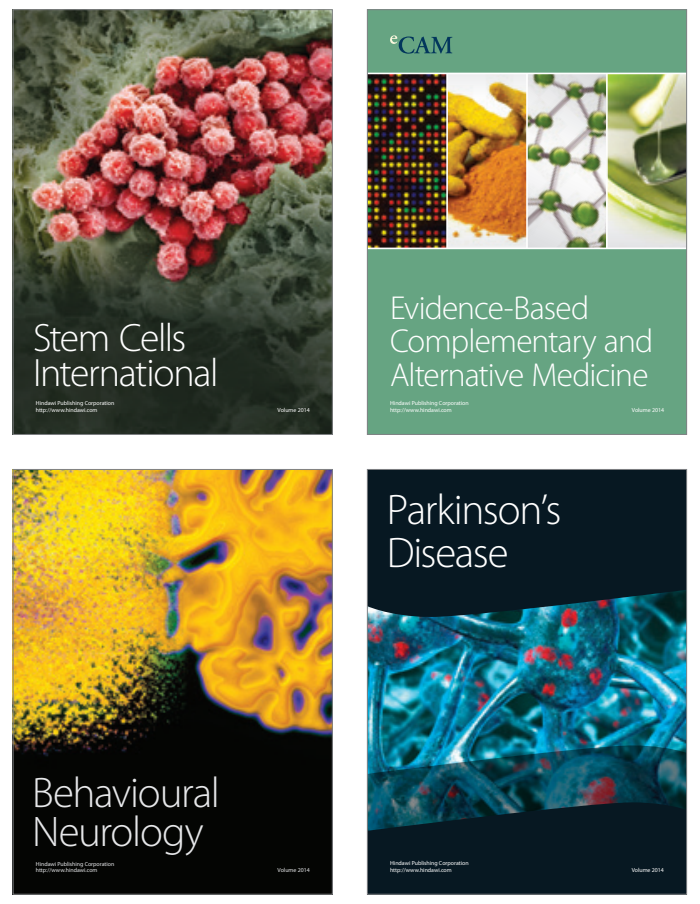
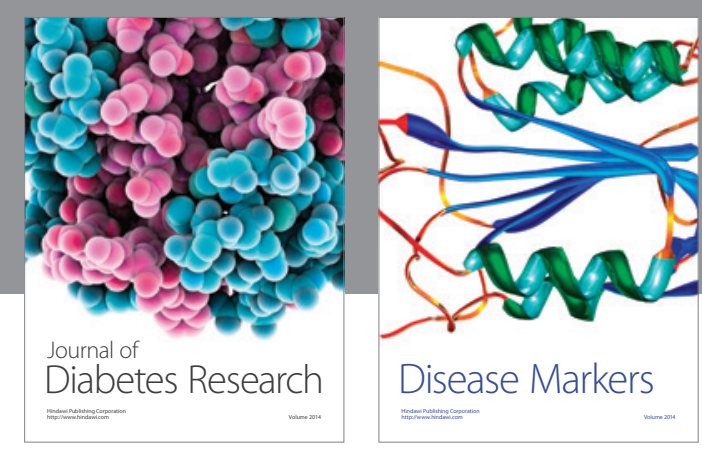

Disease Markers
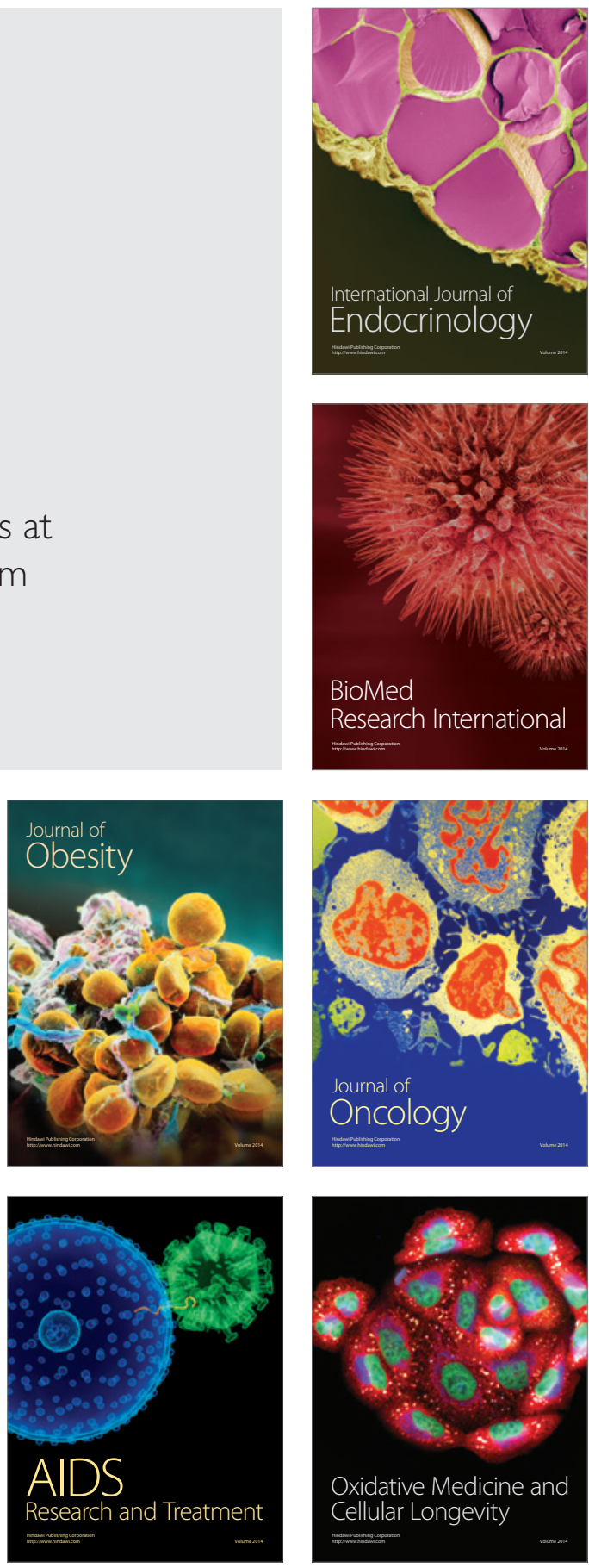